\title{
The Globalization of Liberalization: Policy Diffusion in the International Political Economy
}

\section{Citation}

Simmons, Beth A., and Zachary Elkins. 2004. The globalization of liberalization: policy diffusion in the international political cconomy. American Political Science Review 98(1): 171-189.

\section{Published Version}

http://dx.doi.org/10.1017/S0003055404001078

\section{Permanent link}

http://nrs.harvard.edu/urn-3:HUL.InstRepos:3157884

\section{Terms of Use}

This article was downloaded from Harvard University's DASH repository, and is made available under the terms and conditions applicable to Other Posted Material, as set forth at http:// nrs.harvard.edu/urn-3:HUL.InstRepos:dash.current.terms-of-use\#LAA

\section{Share Your Story}

The Harvard community has made this article openly available.

Please share how this access benefits you. Submit a story.

Accessibility 


\title{
The Globalization of Liberalization: Policy Diffusion in the International Political Economy
}

\author{
BETH A. SIMMONS Harvard University \\ ZACHARY ELKINS University of Illinois
}

\begin{abstract}
$O$ ne of the most important developments over the past three decades has been the spread of liberal economic ideas and policies throughout the world. These policies have affected the lives of millions of people, yet our most sophisticated political economy models do not adequately capture influences on these policy choices. Evidence suggests that the adoption of liberal economic practices is highly clustered both temporally and spatially. We hypothesize that this clustering might be due to processes of policy diffusion. We think of diffusion as resulting from one of two broad sets of forces: one in which mounting adoptions of a policy alter the benefits of adopting for others and another in which adoptions provide policy relevant information about the benefits of adopting. We develop arguments within these broad classes of mechanisms, construct appropriate measures of the relevant concepts, and test their effects on liberalization and restriction of the current account, the capital account, and the exchange rate regime. Our findings suggest that domestic models of foreign economic policy making are insufficient. The evidence shows that policy transitions are influenced by international economic competition as well as the policies of a country's sociocultural peers. We interpret the latter influence as a form of channeled learning reflecting governments' search for appropriate models for economic policy.
\end{abstract}

$\mathbf{O}$ ne of the most important developments over the past three decades has been the growing willingness of governments to open up the national economy to global market forces. The widespread rollback of policies that block the free movement of goods and capital has affected the quality of life for millions of the world's citizens. Economists reckon the gains to developing countries from a liberalized capital regime to be in the billions of dollars of added GDP growth (Dobson and Hufbauer 2001; Soto 2000). Some, however, acknowledge the instability and human insecurity left in liberalization's wake (Kaplinsky

Beth A. Simmons is Professor, Government Department and Faculty Associate, Weatherhead Center for International Affairs, Harvard University, 1033 Massachusetts Avenue, Cambridge, MA 02138 (bsimmons@latte.harvard.edu).

Zachary Elkins is Assistant Professor, Department of Political Science, University of Illinois, 702 South Wright Street, 361 Lincoln Hall, Urbana, IL 61801 (zelkins@uiuc.edu).

The authors thank James Alt, William Bernhard, Henry Brady, David Collier, Ruth Collier, Paul Diehl, James Fearon, Robert Franzese, Jeffry Frieden, Peter Gourevitch, Miles Kahler, Robert Keohane, David Laitin, David Lake, David Leblang, Lisa Martin, Douglas McAdams, Layna Mosley, Kathleen Much, Robert Pahre, Richard Snyder, Michael Ward, and Kurt Weyland for their comments on earlier drafts. Thanks to David Leblang for providing his data on currency crises, and Eduardo Castro and Kathleen MacNamara for providing data on policy change with respect to central bank independence. Previous versions of this paper were presented at the annual meetings of the Midwest Political Science Association and the American Political Science Association, and at Duke University, Notre Dame University, the University of California, Berkeley, and Stanford University. Beth Simmons would like to acknowledge the assistance of students working under the auspices of the Undergraduate Research Apprentice Program at the University of California, Berkeley, as well as sabbatical support from the William and Flora Hewlett Foundation while at the Center for Advanced Study in the Behavioral Sciences, Stanford California Zachary Elkins would like to acknowledge the excellent research assistance of Seden Akcinaroglu and financial support from the Institute for Global Conflict and Cooperation (IGCC), the University of California, Berkeley, and the University of Illinois.
2001; Prasad et al. 2003). These debates have not been resolved. Nevertheless, few policy choices are as fundamental as those that determine how a national economy should engage - or resist - the forces of economic globalization.

Despite its centrality to the economic history of the last third of the twentieth century, we know little about the conditions that underlie the ebb and flow of liberalization worldwide. The political economy literature has typically assumed that the most important political processes to model are largely internal to each national polity. Scholars have built theory about the preferences of domestic actors for liberalization (Frieden 1991; Rogowski 1989), explored the partisan sources of economic and financial policy (Epstein and Schor 1992; Simmons 1994), and linked the rent-seeking behavior of governments to resistance to opening the economy (Alesina, Grilli, and Milesi-Ferretti 1994; Leblang 1997). These benchmark works tend to play down or neglect altogether the role of international politics or broader external social relations. The risk is high that political economy models of economic liberalization have been under- or even misspecified.

As we show, evidence indicates that transitions to economic liberalization cluster in time and space. The question is, What can account for these tides of foreign economic policy liberalization and restriction? A crucial explanation, we believe, lies in policy diffusion, ${ }^{1}$ in which the decision to liberalize (or restrict) by some

\footnotetext{
${ }^{1}$ There is a rich tradition of research on the geographic diffusion of a whole host of political, social, and economic phenomena. In political science, see the work of Walker (1969) and Gray (1973) on the diffusion of policy among the states of the United States, Collier and Messick (1975) on social security, and Tolbert and Zucker (1983) on civil service reform. On democratic diffusion see Huntington 1991, O'Laughlin et al. 1998, and Starr 1991. A parallel set of studies exists in sociology with respect to institutional evolution (e.g., Meyer and Rowan 1977, Powell and Dimaggio 1991, and Strang 1991).
} 
governments influences the choices made by others. ${ }^{2}$ We theorize two broad classes of diffusion mechanisms: one in which foreign policy adoptions alter the benefits of adoption for others and another in which these adoptions provide information about the costs or benefits of a particular policy innovation. In developing these arguments, we explicitly acknowledge the alternatives. For example, liberalization patterns could be a response to commonly experienced phenomena (currency crises, economic recession) rather than the result of interdependent state behavior. Similarly, economic liberalization may simply be the preference of liberal democracies; such preferences alone may lead governments to respond similarly, but independently, to the conditions they face. Both of these processes could lead to highly clustered policy making, but we would not classify either of them as a diffusion process. ${ }^{3}$ For our purposes, they constitute null hypotheses against which accounts of interdependent decision making must compete.

We focus on explaining changes within three foreign economic policy areas, each of which is primarily monetary or financial in nature but has a profound impact on the real economy. The first is liberalization of the current account, which includes foreign debt repayment and payment for goods, services, and invisibles (see Simmons 2000). The second is liberalization of the capital account, or the removal of taxes, quotas, or other rules that discourage the free movement of investment funds into and out of a country (Quinn and Inclan 1997). The third policy is the unification of the exchange rate, or eliminating multiple or tiered systems that can be used to discriminate against particular kinds of transactions or particular trading partners (Reinhart and Rogoff 2002). Together, these three policy areas constitute the principal aspects of international monetary and financial liberalization over the past three decades. We argue that these choices are influenced by the choices of other governments as much as they are by exogenously given domestic institutions or preferences that can be traced back to domestic political or economic structures. Our task is to demonstrate how and why these policy choices diffuse internationally.

One can observe a strong trend, with fits and starts, toward liberalization in these three areas over the past 30 years. In 1967, 25 members of the International Monetary Fund (IMF; $24 \%$ of its membership) had capital accounts that were practically free of restrictions, 38 (37\%) had fully liberalized current accounts, and 75 (73\%) had unified exchange rate systems. By 1996, 54 members $(30 \%)$ had removed virtually all restrictions

\footnotetext{
${ }^{2}$ We use the term diffusion to refer to all processes in which "prior adoption of a trait or practice in a population alters the probability of adoption for remaining non-adopters" (Strang 1991). A host of related phenomena is subsumed under this definition (e.g., imitation, demonstration effects, mimicry, emulation, isomorphism, contagion, dissemination, transfer), which we will assume to be part of the more general phenomenon with which we are concerned.

${ }_{3}^{3}$ We distinguish diffusion processes from diffusion outcomes, or simple clustering in time and space. Processes of policy diffusion are one class of explanation for such clustering, but there are a number of alternative explanations, which we discuss below.
}

on the capital account, while $79(45 \%)$ had liberalized the current account and 158 (or $88 \%$ of the membership) had unified their exchange rate systems. ${ }^{4}$ But more than this trend, what concerns us is that transitions to and from these policies tend to be highly concentrated in certain years and particular regions. For example, the bulk of the transitions to unified exchange rates occurred in the mid-1970s and again in the mid-1990s. Similarly, the late 1960s and mid-1990s were times of high activity in current and capital account liberalization. Policy clusters can be confirmed statistically: The distribution of transition counts (both liberal and restrictive transitions) fits a negative binomial distribution (which assumes clustered data) better than it does the distribution from a random, nonclustered process such as the Poisson. ${ }^{5}$

Foreign economic policy transitions tend to cluster spatially as well. As the 1995 maps in Figure 1 demonstrate, the three economic policies have a distinctly regional cast. But why, exactly, should near neighbors choose similar policies? We suspect that geographical clustering is largely spurious and can be explained by a more precise set of relationships. We suggest two broad diffusion mechanisms for clustered policies: (1) foreign economic policy choices elsewhere can alter the payoffs associated with choosing or maintaining a particular policy, and (2) foreign economic policy choice elsewhere can change the information set on which governments base their own policy decisions. ${ }^{6}$

\section{EXPLAINING CLUSTERED TRANSITIONS IN FOREIGN ECONOMIC POLICY MAKING}

\section{Altered Payoffs}

In this class of mechanisms, the policy decisions of one government alter the costs and benefits of the policy for others. One can think of these decisions as producing externalities that subsequent adopters must factor into their decision calculus. One type of externality is highly material and works through direct economic competition. Another is more ideational and works through the more subjective pressures of prevailing global norms.

\footnotetext{
${ }^{4}$ IMF: Annual Exchange Arrangements and Restrictions, analytical appendix, various issues. Similar trends can be observed with data presented by Prasad et al. (2003).

${ }^{5}$ The Poisson is a rare events distribution that assumes the absence of precisely the two sources of convergence that we purport to disentangle in this article. Specifically, the distribution assumes that the mean equals the variance, which, in an event count, implies that events occur independently and that the susceptibility of a particular event is homogeneous across units, which in this case is years (King 1989). If there is overdispersion (variance greater than the mean) - an effect of highly clumped data - then the Poisson will not fit the data well. The negative binomial, on the other hand, is less restrictive and treats the variance as a parameter to be estimated. For each set of policy reversions, we performed a chi-square test of the equivalence of distributions. In each case, a likelihood-ratio test reveals that the data on policy choice fit a negative binomial distribution significantly better than they do a Poisson.

${ }^{6}$ Policy innovation elsewhere may affect both payoffs and information, but we view these mechanisms as analytically, if not always empirically, distinct.
} 


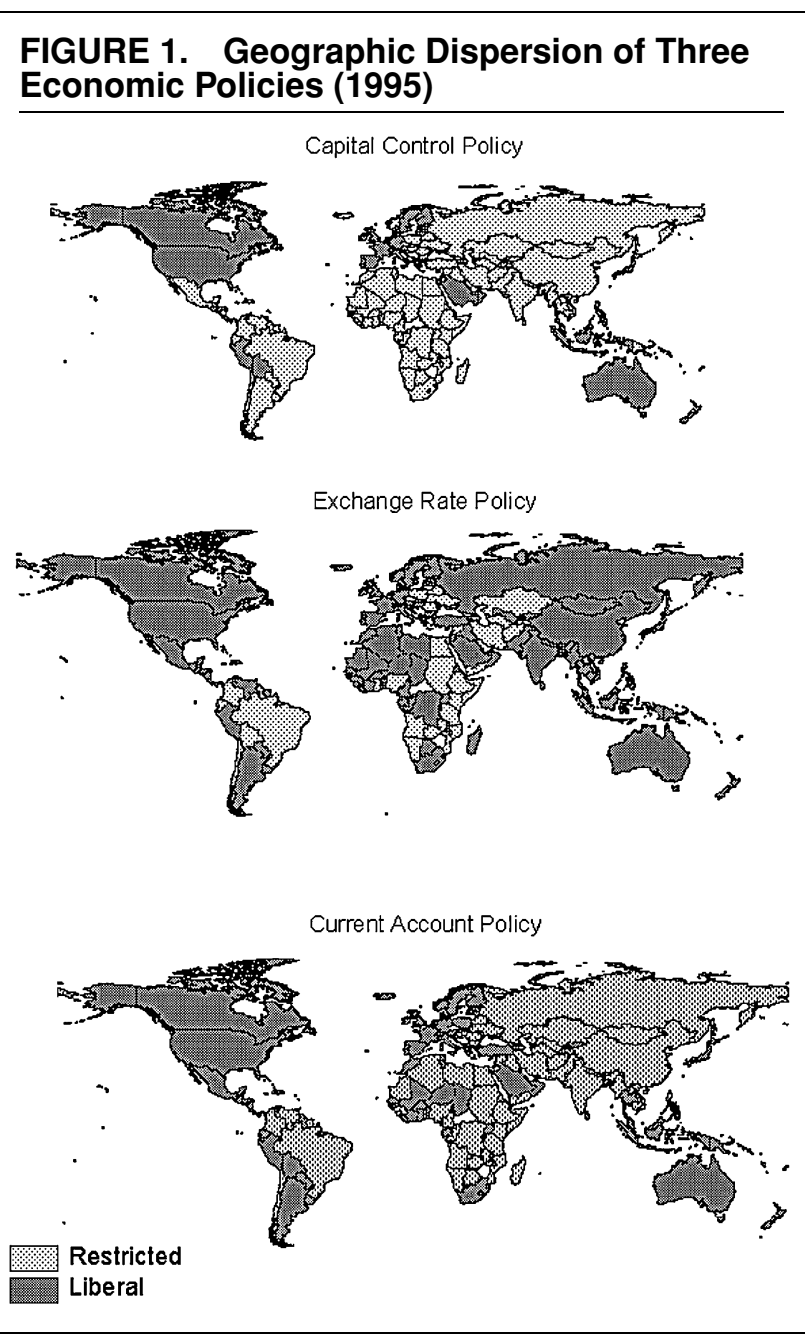

Altered Material Payoffs. One of the important insights of economists who pioneered the early interdependence literature was that economic policies adopted in one country can have economic effects elsewhere, with profound consequences for policy making (Cooper 1968). These insights informed a generation of political economy work concentrated on issues of macroeconomic policy coordination among the major economies (Hamada 1985; Iida 1999).

International markets for goods and especially for capital are the conduit for policy interdependence in these models. Here we focus on competition among policy makers to attract capital and international business generally as a means to enhance aggregate economic growth (Stockman and Hernandez 1988). Policy liberalization in country A may make it a relatively more attractive venue for investment or conducting commercial relations. Indeed, economists have stressed that capital and trade respond positively to the signal that policy liberalization sends (Bartolini and Drazen 1997). When a country's foreign competitors liberalize, traders and investors are drawn to locations where they can do business more freely and securely. Anticipating this outcome, country B may feel competitive pressures to match its rival's liberal policy. This phenomenon sets up the possibility of competition among jurisdictions, at least on the margins, for international economic activity.

In this model, governments act strategically in order to attract economic activity to their jurisdiction with the ultimate aim of boosting aggregate growth. Pluralist renditions emphasize the preferences of electorally significant firms or groups in clarifying to leaders the interests they have in such policies (Encarnation and Mason 1990; Goodman and Pauly 1993). In more statist versions, decision makers take such actions regardless of the immediate preferences of domestic political groups (Krasner 1985); in the medium run, they are gambling on an aggregate growth payoff for which, presumably, they will be rewarded by continued political support. In each case, the government faces incentives to anticipate and match decisions made outside its jurisdiction, rather than waiting passively for these decisions to work their way through the international economy, the domestic economy, and the domestic electoral system. In an international environment that is assumed to be institutionally thin and nonhierarchical, the result is competitive pressure to implement capital- and tradefriendly policies when major competitors have done so.

Note that this model does not predict universal convergence on liberalization. It predicts convergence toward either restrictive or liberal policies among competitors. We assume that a decision maker has good information about the identity of competitors, their policy choices, and the material consequences of matching or failing to match their policies. The model leads to the following prediction:

\section{Governments' liberalization policies will be in- fluenced by the policies of their most important foreign economic competitors.}

Altered Reputational Payoffs. Changes in prevailing global ideas and the practices they entail create externalities for governments as well. One of the hallmarks of the current trend toward globalization is the ascendancy of theories that emphasize market mechanisms as engines of economic growth (Gore 2000; McNamara 1998; Williamson 1993). The spread of liberalization both reflects and buttresses the power of a neoliberal ideational consensus.

Ideational consensus is a potential externality because it alters the reputational payoffs associated with policy choice. As growing numbers of important actors articulate theories and implement practices that reflect a normative consensus, the legitimacy of these ideas gathers steam. In the absence of ideational consensus, heterodox policies are difficult to distinguish and are readily tolerated. But theoretical consensus on an appropriate economic model raises the intangible costs of nonconformity. Perceived policy failures associated with "heterodoxy" will suffer greater public condemnation than similar failures of conforming policy. Governments that resist ideational trends face reputational consequences that cast doubt on their approach to the economy and potentially the legitimacy of their governance. 


\section{FIGURE 2. Threshold Model of Policy Adoption}

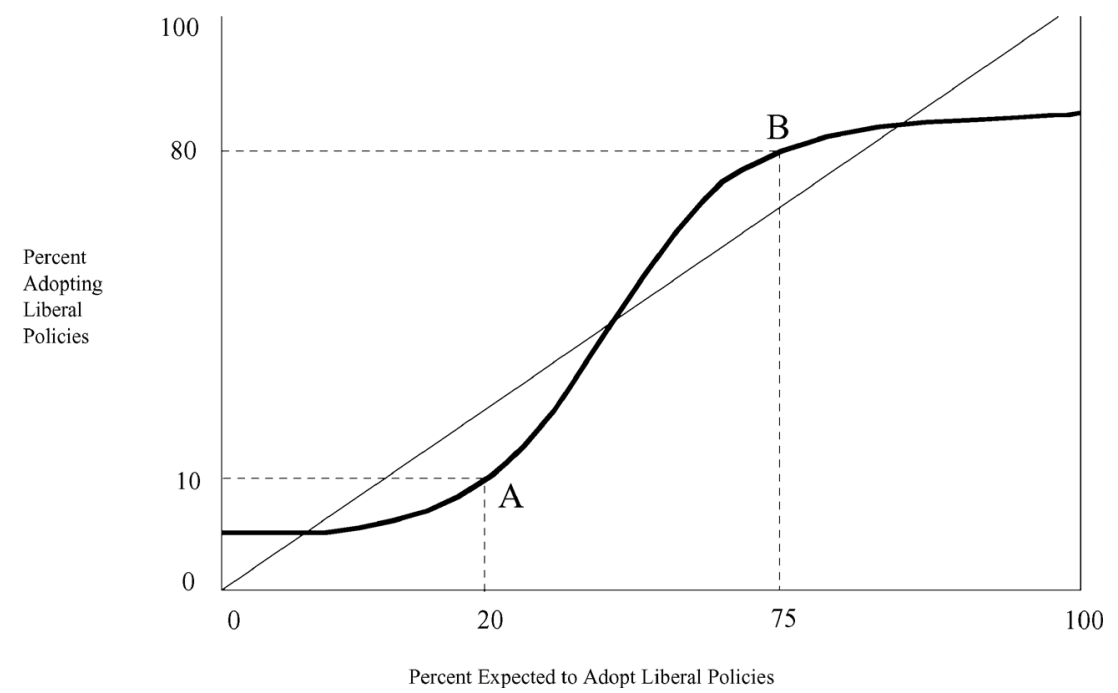

The logic that links normative consensus to legitimacy externalities may be reflected in the "tipping," or "threshold," models that Schelling (1978) and Granovetter (1978) have described. The basic intuition in these models is that most governments are highly sensitive to the number, or proportion, of other countries that have adopted a particular policy stance. The idea of "thresholds" or "critical mass points" is a useful (although not necessary) device for understanding the process.

Figure 2 illustrates the classic effect of Schelling's conception of thresholds on the probability of adopting a particular policy. Imagine a group of actors, each of whom will adopt a given practice only if a critical mass of others adopt. Assuming that the distribution of the various critical mass points is normal, we can add them and produce the s-curve in Figure 2 (which depicts the mean critical mass point around $50 \%$ ). Points on the curve represent the proportion of actors who would adopt a policy given the proportion of the population that is expected to adopt. In this stylized scenario, one can see that a small set of actors (about $5 \%$ ) would adopt the policy even if no one else is expected to do so. Similarly, a small percentage of actors (about $15 \%$ ) at the top of the curve will not adopt even if they expect everyone else to adopt. The $y=x$ line helps demonstrate the equilibria that result from this dynamic. Points on the curve under the identity line will resolve to the bottom of the curve (at its intersection with the identity line), because the critical proportion that actors require for their adoption is always higher than the number who would adopt at that level. One can see the opposite dynamic for points above the identity line, where the $x$ and $y$ variables also reinforce one another, but this time produce an equilibrium point at the upper intersection of the curve and the identity line.

Tipping models capture the dynamics of global norms fairly well. For reputational reasons, the propor- tion of others adopting may matter a great deal. Such reasoning implies a clear empirical expectation:

The proportion of liberalizations in the sample at large should influence a government's decision to liberalize.

\section{New Information}

A conceptually distinct motor for policy diffusion is informational. In contrast to the discussion of payoffs above, this approach assumes that governments often lack the crucial information they need to understand the consequences of economic policy innovation. ${ }^{7}$ Innovations elsewhere provide information on policy consequences that may be more or less relevant in a particular case. Governments are assumed here to use available information in a rational fashion to maximize the chances of their own policy success. Sometimes such policy learning involves deliberate attention to foreign models and their outcomes (see, e.g., Westney's [1987] description of Japanese statecraft in the 1800s). Foreign models can encourage or expedite adoption by inserting a policy innovation on a legislature's agenda. A foreign model may also offer a ready-made answer to ill-defined domestic pressure for "change" and "innovation." Or it may legitimate conclusions or predispositions already held or add a decisive data point in the evaluation of alternatives (Bennett 1991). But what "lessons" do governments actually learn in the economic policy realm? We hypothesize that they may learn from "success," via communication networks, and from cultural reference groups.

\footnotetext{
${ }^{7}$ A consistent theme in recent research has been the uncertainty surrounding the liberalization process. A recent study by staff of the IMF concludes that basic questions about the optimal pace and sequencing of financial integration are unresolved (Prasad et al. 2003, 5).
} 
Learning from Success. The most obvious sources of lessons for economic policy making are those that seem to "work." By mechanisms consistent with theories of Bayesian updating, governments are likely to follow the lead of those countries whose economic consequences appear to have been notably favorable. Thus the Japanese "miracle" provided an economic model for much of Asia and beyond in the 1970s and 1980s, though it has been a far less attractive model during the doldrums of the 1990s. Chile, too, is often cited as a relevant "success story" for liberalization of emerging market economies, from Latin America to Asia to Eastern Europe (Edwards and Edwards 1992).

Learning from success need not depend on the ability of the government to reason in a sophisticated manner about the links between a policy and its apparent outcome. Indeed, "learning" can be quite superficial, and it often involves linking a highly salient outcome with a policy innovation without complete information about the causal connections. The apparent success of others may in fact be a cognitive short-cut to assessing policy consequences; the relevant question in this process is, What policies are the high achievers pursuing? If this form of learning is important, we should expect governments to be influenced by the policy innovations of the best-performing economies.

Learning through Communication. Above we assumed that learning was channeled by salient facts. Another possibility is that it is primarily conditioned by informational networks themselves. The exchange of information among connected actors is the presumed motor behind diffusion in most sociological studies (Rogers 1995; see also Axelrod 1997). In these models, information is largely channeled along specific actor networks. The cognitive process is dominated by an availability heuristic, in which actors unable to retrieve a full sample of information base their decisions on only those instances that are available to them (Kahneman, Slovic, and Tversky 1982). The result is that the choice set of policy makers will be limited to policies of states that are immediately accessible to them.

One can readily identify the kinds of network and communicative links that could contribute to learning with respect to monetary and financial liberalization. Direct contacts at the intergovernmental level may reflect well-established channels of communication: Frequent intergovernmental meetings at multiple official levels can transmit information to policy makers about "what works" in other settings. It is well documented that the process of negotiating and maintaining institutional affiliations may create opportunities to learn and persuade (Haas 1959). Conversely, where official contacts are infrequent, information is less likely to be transmitted and less likely to become salient to decision makers.

Policy diffusion may follow communication channels mediated by private actors as well. Business people may transmit ideas about appropriate economic policy by looking to the experiences of the countries with which they have especially intense trading contacts. Lessons drawn from these contacts may inform the shape of the demands they make on their own governments, thus feeding into the demand side of the policy equation. This argument suggests that policy diffusion should be strongest among governments that are in especially close communication. We should expect a positive relationship between policies of governments with extensive opportunities to share information about the consequences of economic policy innovation.

Learning from Cultural Reference Groups. Actors in uncertain and information poor environments rationally seek information relevant to their own policy context. Learning takes place at least partially through analogy, and lessons are viewed as more relevant the extent to which a foreign case is viewed as analogous. The IPE literature readily distinguishes between "advanced industrial," "emerging," and "developing" countries but completely overlooks a far more salient identity marker that may shape the emulation process: cultural similarity.

Cultural propinquity is a nonobvious yet highly plausible explanation for policy emulation, even in as material an issue area as international finance. Cultural factors underlie economic and financial structures to a greater extent than is often realized. Granato, Inglehart, and Leblang (1996) have shown that cultural values are important to economic development. Cargill and Parker $(2001,2)$ note, in their study of financial liberalization in China, that China adopted the Japanese style of finance for "shared cultural and historical reasons." The experience of Egypt with financial liberalization is typically cited as the appropriate source of lessons for "Arab banking systems" (Wahba and Mohieldin 1998). Indeed, a new generation of research explores the ways in which culture has reasserted itself despite the globalization of markets (Beng-Huat 1999; Chun 2000; Goff 2000).

Unlike organizational sociologists, who have concentrated on the apparently nonrational adoption of policy models reflecting "world culture" (Meyer and Rowan 1977; Powell and DiMaggio 1991; Scott and Meyer 1994), we argue that cultural emulation reflects reasonable efforts to learn from the most appropriate available examples of policy innovation. We are interested in testing a constructivist-inspired hypothesis: Ideas about appropriate models are likely to reflect deep identity concerns (Checkel 1993; Risse-Kappen 1994; Ruggie 1975). Sociologists have long assumed that shared beliefs and values shape the channels along which ideas flow (Rogers 1995, 274). In fact, the voluminous literature on diffusion and social influence has found that entities that share similar cultural attributes tend to adopt the same practices. This is true not only of individual behavior like teen smoking (Coleman 1960) and voting (Brady and Sniderman 1985; Lupia and McCubbins 1998) but also of collective behavior with respect to corporations (Davis and Greve 1997), nonprofit organizations (Mizruchi 1989), states within federations (Walker 1969; Rose 1993), and indeed nationstates (Deutsch 1953). The most plausible explanation of this finding is that actors negotiating a complex set of political choices regard the actions of actors with 
perceived common values as a useful guide to their own behavior.

But why should cultural groups be relevant reference groups? For one thing, cultural markers are highly visible. If decision makers know one thing about another country, it is usually the language its citizens speak or the general tenor of the cultural traditions they practice. Moreover, common culture embodies subjective notions of identity contained in assumptions of commonly shared values and social purposes. The policies of culturally similar countries are perceived to (and in fact may) contain highly relevant information on the appropriateness of a particular policy in a specific context of shared values. This perceived similarity may provide a cognitive short-cut for an individual or a focal point to limit cycling over alternatives in a group decisionmaking context. Furthermore, models used by favored cultural groups may provide a persuasive rhetorical spin in the debates that accompany policy evaluation (on the importance of rhetoric and persuasion to the policy evaluation process see Majone 1989). Following the lead of cultural reference groups may even provide a way to mitigate the perceived threats to cultural identity posed by globalization. ${ }^{8}$ In each case, perceived cultural affinity assists in selecting the relevant models, or "reference groups," that inform policy development. ${ }^{9}$ Admittedly, economic policy making - a practice with very material ends and theoretical underpinnings that make no explicit concessions to culture-may be immune to culturally channeled learning. But given a high degree of uncertainty about the consequences of a particular policy shift, governments may be influenced to follow the lead of a culturally or socially similar group of states.

\section{We expect that cultural similarity will be a posi- tive predictor of policy diffusion among states.}

\section{DATA AND ANALYTICAL METHODS}

The empirical problem now is (1) to identify meaningful measures of the pressures from altered payoffs and channeled forms of learning and (2) to estimate their effects on the liberalization and restriction of foreign monetary and financial policy, while controlling for a reasonable battery of nondiffusion effects.

\section{Dependent Variables}

Our dependent variables are transitions in each of three policy areas-capital account openness, current account openness, and exchange rate unification. (See Table 1 for descriptive statistics and sources.) Each of the variables is a binary measure of whether the government has or has not imposed restrictions (or, in the exchange rate case, a tiered or multiple system) in the

\footnotetext{
${ }^{8}$ On the importance of perceived cultural threats in the Egyptian case, see Amin 1981.

${ }^{9}$ Rosenau $(1990,213)$ terms these reference groups "cathectic," suggesting that decision makers have a strong cultural sense of whom their nation should look like.
}

given year (with policy liberalization $=1$ ). The data are from the annual IMF volumes on exchange restrictions and controls (Analytical Appendices; various issues). These measures have been criticized on a number of grounds, but for our purposes they are appropriate.

One concern is that the dichotomous measure masks the complexity and intensity of restrictions. For at least one of the dependent variables (capital controls), data with finer gradations do exist, though for a smaller sample (Quinn 1997). All things being equal, we would prefer to use a more finely grained measure. Nevertheless, our purpose here is to model major policy shifts glob$a l l y$, and the cost in sensitivity with the IMF's data is balanced by their comprehensive coverage across time and space. It is less important, for our purposes, to capture the nuance than it is to capture the foundational policy demarches for a wide range of countries around the world. Nonetheless, it is crucial that our use of dichotomous data does not misrepresent true trends. For this reason, we compared the IMF capital control measure with Dennis Quinn's more nuanced measure for the countries these two datasets have in common (namely, 27 OECD countries between 1967 and 1997). The overall correlation between the dichotomous IMF data and the polychotomous Quinn data is 0.65 , suggesting that the former do not suffer remarkably from unreliability. The Quinn data and the dichotomous IMF data diverge most in more recent years. These are years for which the OECD countries have already crossed the threshold to liberalization by our cruder measure. Quinn's measure continues to pick up nuances in degrees of liberalization beyond this threshold, causing the correlation in later years to come somewhat unhinged.

The existence of a superior but more limited dataset provides an opportunity to check the validity of the globally available dichotomous measure. The construct validity of a measure of capital controls may be judged by the comparative accuracy of its prediction of the volume of capital flows (see Collier and Adcock 2002 for a useful clarification of validity issues). When we regress gross private capital flows as a percentage of GDP on the dichotomous measure and on Quinn's polychotomous measure (for the 27-country overlapping sample), both measures appear highly statistically and substantively significant, after accounting for serial autocorrelation in the time series with a fixed effects model. The $R^{2}$ statistics for similar models employing the measures successively are slightly higher for the IMF measure than for the Quinn data for the same country sample ( 0.57 compared to 0.53$)$, and the standard error of the model (perhaps a better measure than $R^{2}$ because of the difference in scale of the two measures) is lower for the IMF measure. And if we focus just on the 1990s-the period for which these measures diverge- the dichotomous measure predicts even more of the variance with respect to capital flows than does the more nuanced Quinn measure $\left(R^{2}\right.$ of 0.64 compared to 0.57 and standard error of roughly 68 compared to 127). These tests suggest that the IMF's dichotomous measures, although crude, are quite likely to be valid constructs for the phenomenon we have in mind. Finally, as we need global data to test arguments 


\begin{tabular}{|c|c|c|c|c|c|c|}
\hline $\begin{array}{l}\text { Mechanism or } \\
\text { Concept }\end{array}$ & Explanatory Variable & Mean & SD & Minimum & Maximum & $\begin{array}{c}\text { Data } \\
\text { Source(s) }\end{array}$ \\
\hline \multirow[t]{3}{*}{ Dependent variables } & Capital account policy & 0.22 & 0.42 & 0 & 1.0 & (1) \\
\hline & Exchange rate policy & 0.73 & 0.44 & 0 & 1.0 & (1) \\
\hline & Current account policy & 0.46 & 0.50 & 0 & 1.0 & (1) \\
\hline \multirow{2}{*}{\multicolumn{7}{|c|}{ Altered payoffs }} \\
\hline \multirow{3}{*}{$\begin{array}{l}\text { Material } \\
\text { Competition }\end{array}$} & & & & & & \\
\hline & $\begin{array}{l}\text { Policies of capital } \\
\text { competitors }\end{array}$ & 2.25 & 1.3 & 0 & 10 & $(1,3)$ \\
\hline & $\begin{array}{l}\text { Policies of trade } \\
\text { competitors }\end{array}$ & 1.93 & 1.40 & 0 & 6.36 & $(1,2)$ \\
\hline \multicolumn{7}{|l|}{ Reputational } \\
\hline Global norms & Mean global policy & 2.26 & 0.31 & 1.80 & 3.4 & (1) \\
\hline \multicolumn{7}{|l|}{ New information } \\
\hline Learning from success & $\begin{array}{l}\text { Policies of high-growth } \\
\text { countries }\end{array}$ & 2.8 & 0.68 & 1.50 & 3.9 & $(1,10)$ \\
\hline \multirow[t]{3}{*}{ Communication networks } & Policies of trade partners & 5.08 & 2.43 & 0 & 10 & $(1,2)$ \\
\hline & Policies of BIT partners & & 3.69 & 0 & 10 & $(1,5)$ \\
\hline & Policies of PTA partners & 2.28 & 2.07 & 0 & 10 & $(1,4)$ \\
\hline \multirow[t]{3}{*}{ Cultural similarity } & Policies of religion partners & 2.22 & 1.14 & 0 & 8.6 & $(7-9)$ \\
\hline & Policies of colonial partners & 1.69 & 1.68 & 0 & 10 & $(6)$ \\
\hline & $\begin{array}{l}\text { Policies of language } \\
\text { partners }\end{array}$ & 3.11 & 2.18 & 0 & 10 & (6) \\
\hline \multicolumn{7}{|l|}{ Control mechanisms } \\
\hline \multirow[t]{5}{*}{ Economic conditions } & Current account/GDP $(t-2)$ & -3.83 & 10.99 & -240.52 & 70.21 & (11) \\
\hline & GDP growth & 4.08 & 14.27 & -76.82 & 699.90 & (11) \\
\hline & $\begin{array}{l}\text { GDP per capita } \\
\text { (in thousands) }\end{array}$ & 3.31 & 5.62 & 0.03 & 37.42 & (10) \\
\hline & Interest rates & 6.60 & 2.45 & 3.02 & 14.08 & (12) \\
\hline & Currency crisis $(t-1)$ & 0.14 & 0.35 & 0.00 & 1.00 & (20) \\
\hline \multirow[t]{2}{*}{ External political pressures } & Use of IMF credits & 0.76 & 0.42 & 0 & 1 & (17) \\
\hline & Foreign aid (per capita) & 55.88 & 157.28 & -75.31 & $2,337.98$ & (17) \\
\hline \multirow{5}{*}{ Domestic political conditions } & Degree of openness & 66.78 & 44.12 & 4.99 & 423.41 & $(10,11)$ \\
\hline & Democracy & 3.78 & 4.34 & 0.00 & 10.00 & (13) \\
\hline & Nationalist e & 1.45 & 3.52 & 0.00 & 10.00 & (14) \\
\hline & Central bank independence & 0.14 & 0.35 & 0.00 & 1.00 & (18) \\
\hline & / legal tradition & 0.34 & 0.47 & 0.00 & 1.00 & (19) \\
\hline \multirow[t]{2}{*}{ Geography } & Policies of border countries & 2.38 & 3.51 & 0 & & $(15,16)$ \\
\hline & Policies of neighbors & 2.40 & 0.92 & 0 & 7.89 & $(15,16)$ \\
\hline \multicolumn{7}{|c|}{ 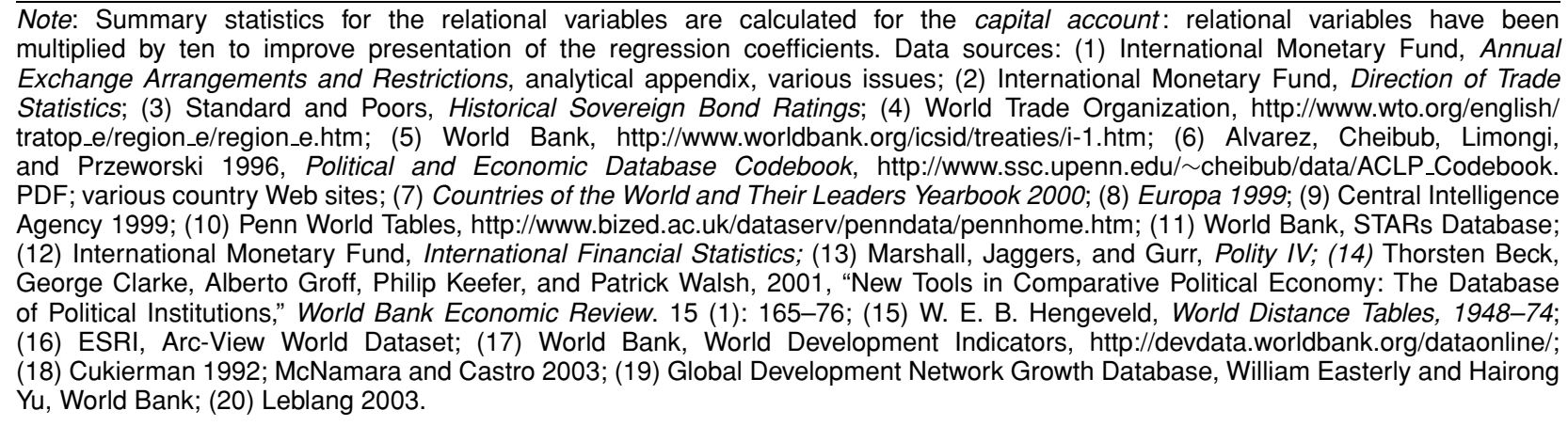 } \\
\hline
\end{tabular}

about global diffusion processes, and as we employ event history methods (discussed below), the dichotomous measure is most appropriate.

Another concern is that the IMF measures do a better job of measuring "announced" policy than they do "actual" policy. The validity analysis of the IMF capital control measure above suggests that this difference is negligible. Nevertheless, with respect to the exchange rate data, some authors have questioned the correspondence between these reports and actual currency behavior. Reinhart and Rogoff (2002) have developed a measure of exchange rate unification based on actual rates rather than reported government policies. Because their data are thought to be the state of the art among economists, we coded the descriptions from their qualitative appendix to see to what extent they accord with the extant IMF data. Our dichotomous coding of the Reinhart/Rogoff data 
with respect to exchange rate unification correlated quite highly with the IMF data (the datasets agree in $82 \%$ of the 3449 country-years they had in common between 1967 and 1997). Disagreement between the Reinhart/Rogoff data and the IMF's was strongest in the early 1970 s, the period of breakdown in the Bretton Woods system of fixed rates.

We checked to see whether the roughly $20 \%$ of cases of disagreement involved a systematic bias by the IMF but found that the "off-diagonals" in a cross tabulation were roughly equally distributed. There was a slight tendency for countries to report a unified exchange rate when the behavioral measure indicated otherwise, but these cases account for at most about $4 \%$ of the total number of cases. As above, we also tried to confirm the validity of the IMF data. Because multiple rate systems are sometimes used to discriminate against classes of imports or importers, we compared regressions of imports as a proportion of GDP on the two measures, taken individually and then together. In this case, the Reinhart/Rogoff measure did slightly better at predicting imports in a fixed effects model than did the IMF measure. For this reason, we have replicated all exchange rate models with the Reinhart/Rogoff data. ${ }^{10}$ All of the main findings are robust to the use of either dataset (see subsequent footnotes for details).

\section{Diffusion Variables}

In order to assess the source and strength of policy diffusion paths, we must construct variables that plausibly indicate changing payoff structures (material or reputational) and new sources of salient policy information. Under these two broad rubrics, we seek to identify a country's various competitive, normative, communicative, and cultural influences and combine this information with the policy "cue" transmitted along that network. The growing field of spatial econometrics offers a useful set of methods to incorporate these kinds of variables (Anselin 1988). ${ }^{11}$ Spatial regression models handle spatial dependence in one of two ways. One is to specify the spatial dependence in the error term (spatial error models). This method is appropriate when spatial dependence is nothing more than a nuisance that biases the interpretation of the parameters of interest. When, as in our case, spatial dependence is itself the focus, researchers include spatial terms as regressors in the model (spatial lag models).

Spatial lag models treat spatial dependence in the same way that time-series models treat serial correlation. Instead of lagging the value of the dependent variable one unit in time, one "lags" it one unit in space. The spatial lag is the weighted average of the dependent variable in the actor's "neighborhood." The neighborhood is mapped by an $N \times N$ spatial weights matrix conventionally labeled $W$. Thus the spatial lag

\footnotetext{
${ }^{10}$ Full results using the Reinhart/Rogoff exchange rate data are available from the authors on request.

11 A parallel set of methods has developed within network analysis. See, for example, Marsden and Friedkin 1993.
}

for country $i$ can be written

$$
W y_{i}=\sum_{j=1, \ldots, N} W_{i j} \cdot y_{j}
$$

where $W$ is the spatial weights matrix and $y_{j}$ is the dependent variable for country $j$. In matrix form we write the relationship $W y$, where $y$ is an $N \times 1$ vector of observations on the dependent variable. These measures vary by year as well. ${ }^{12}$

As with time-series models, the spatial dependence can be modeled as an autoregressive or as a moving average function, depending on our assumptions about the effect's rate of decay. Because we expect spatial effects to reverberate throughout the network and not just from the closest actor, we adopt an autoregressive function. We can express such a model as

$$
Y=\rho W y+X \beta+\varepsilon,
$$

where $\rho$ is a spatial autoregressive coefficient, $W$ is the $n \times n$ spatial weights matrix, $X$ is a vector of nondiffusion regressors with coefficients $\beta$, and $\varepsilon$ is a vector of error terms. ${ }^{13}$

In geographic models, the spatial weights matrix, $W$, is often a matrix of geographic distances among units. In our case, we are interested in measuring influence along other channels controlling for geography: through competitors whose policies alter material payoffs, through norms that gain global adherents and thus alter reputational payoffs, and through linkages that alter the information set that informs policy decisions. The elements of $W$ differ according to the nature of the measure of "distance" between units. These measures come in two principal forms: (1) direct bilateral data that record a level of interaction between states (e.g., amount of trade, number of telephone calls) and (2) affiliation data that identify shared membership in various groups (e.g., regional trade groups and language communities).

Indicators of Altered Payoffs. We have theorized that altered payoffs spur policy liberalizations and that these payoffs may be material or reputational. Competitive economic pressures are a clear example of the former. In order to measure the effect of competitive mechanisms, we developed indicators of "competitive distance" for two arenas of competition: the export market for goods and services and the capital market. For the export market we have created two measures. The first registers the degree to which nations compete in the same foreign markets. ${ }^{14}$ Because an importing country may find ways to reciprocate or reward policy liberalization in country A, country B has an incentive to liberalize to the extent that $\mathrm{A}$ and $\mathrm{B}$ compete for market share within that third market. Using the bilateral

\footnotetext{
${ }^{12} \mathrm{~W}$, then, is an $N \times N \times T$ matrix and $y$ is an $N \times T$ matrix.

13 In the models reported below, we measure the policies of the tenth of the sample closest to each country, by each measure. We also tested models that allowed for a more gradual rate of decay in the lag by weighting the dependent variable by the distance to all other countries in the sample. The results were, on the whole, fairly similar for these different lag structures.

14 For a similar approach see Finger and Kreinen 1979 and Wasserman and Faust 1994.
} 
direction of trade data available from the IMF, we produce an $n \times n \times t$ matrix of correlations (between countries) across each country's total exports to each of the 182 partner countries. The result is a matrix of yearly, dyadic measures of the degree to which nations possess the same trade relationships. We use these "distances" to identify the tenth of the sample most competitive with each country in each year. The mean of the dependent variable for this group is the spatial lag. Another way to measure export competition is to observe the similarity between countries according to their proportion of exports in various sectors. This measure was constructed by calculating the correlations between countries, by year, across a set of nine variables that scored the countries on the percentage of their exports in nine different sectors. We use these correlations, together with the dependent variables of other countries, to calculate the spatial lag in the way described above. We expect a positive association between both measures of policies of close trade competitors and the dependent variable.

Competitors for investment capital are also likely to be salient models for policy makers. Because investors want the freedom to repatriate their assets, among otherwise similar investment venues they will favor countries that allow for the liberal movement of capital and currency at nondiscriminatory exchange rates. Ideally, we seek an indicator that allows us to predict which countries will compete for the same pool of international capital. We begin by assuming that international investors' decisions depend on their varying tastes for risk. Portfolio theory suggests that investors will want to create a portfolio with a share of low-risk, medium-risk, and high-risk investments (according to their tastes). Investors may decide, for example, that $10 \%$ of their portfolio will be reserved for high-risk, potentially highreturn investments. Given this assumption, it is reasonable to posit that countries that pose similar risks are close substitutes from an investor's point of view. (The United States, we assume, does not primarily compete with Argentina for foreign capital, whereas Brazil might.) Our measure groups countries by their yearly Standard and Poor's sovereign bond rating and calculates the mean policy score (for each policy area) for a country's rating category for each year. ${ }^{15}$ If competition over the same "slice" of international capital provides incentives to liberalize, then we expect a positive coefficient.

Using bond ratings in this way is unprecedented and deserves some exposition. In a model predicting economic policy, one may be concerned with the potential endogeneity of bond ratings. It is reasonable to think that analysts at Standard and Poor's are accounting for a country's economic policy in their assessment of the risk of default of the country's bonds. But policiesmuch less the specific policies we analyze here-appear to play a minor role in the rating system. As Stan-

\footnotetext{
${ }^{15}$ Because it is possible that the policies themselves help determine the bond ratings, we experiment with models that lag the ratings by two and three years. We find that the results do not change significantly with this modification.
}

dard and Poor's describes their methodology, ratings are constructed by an informal (and subjective) combination of one to five scores in eight areas, one of which theoretically could include an assessment of fiscal policy. Empirical analyses suggest that the ratings depend overwhelmingly on macroeconomic indicators of public debt and inflation (Cantor and Packer 1996; Haque, Mathieson, and Nelson 1997), and not the specific policies of interest here.

Nevertheless, we are sensitive to the possibility of such endogeneity and, accordingly, have developed another measure to identify capital competitors in order to corroborate our results. Assuming that potential foreign direct investors are concerned with a country's human assets as well as its technological and communications infrastructure, we reason that countries with similar educational and infrastructural profiles will compete for the same pool of capital. We compare such investment profiles by calculating correlations, by year, between countries across roughly 15 educational and infrastructural variables selected from the World Bank World Development Indicators. As we do for the export competition measure, we use these distances between countries to identify the tenth of the sample "most similar" to each country in investment profile. The spatial lag is the mean of the dependent variable for this group of countries.

We have also argued that changes in less tangible payoffs such as legitimacy and prestige might be influenced by the prevalence of increasingly global norms, theories, or beliefs embraced by governments elsewhere. Heterodox policy failures are likely to earn a government more criticism than would policy failures that are consistent with a global consensus about what constitutes wise, sustainable economic policy. We measure global norms with the yearly mean of the dependent variable across all countries in the sample. One may think of this indicator as a measure of unchanneled diffusion pressure, something diffusion scholars sometimes call homogeneous, as opposed to heterogeneous, mixing (Strang 1991).

Indicators of Informational Influences. Our second cluster of arguments concerns changes in the information set governments face. Our first set of information indicators taps learning from apparent success (rational Bayesian updating). Many complex measures of success could be devised, but we opt for a highly visible and well-publicized bottom line: growth rates. Our measure is the proportion of liberal (or restrictive) policies of the top growth decile. The higher this proportion, the clearer the message that liberalization "works."

Our next set of indicators concerns communication networks. At the official level, information about economic policy options can be transmitted through negotiations and discussions among the members of economic agreements and groupings, such as the European Union or NAFTA. ${ }^{16}$ Another plausible channel for

\footnotetext{
${ }^{16}$ Common membership in a PTA is likely to be endogenous (explained, for example, by shared attitudes toward policy liberalization), but our formulation of the dependent variable (actual policies
} 
communicating expectations and information about capital account openness is bilateral investment treaties (BITs). Again, for each country-year, we calculate average policy scores weighted by PTA and by BIT partnerships. These common memberships should predict channeled policy diffusion, based on the diffusion of policy-relevant information.

Information can also flow between decision makers via private channels. Private actors who are exposed to liberal foreign regimes for the movement of goods and services may become convinced of the virtues of these arrangements and attempt to persuade their governments to liberalize. Learning may even take place (though less plausibly) at the mass level: Extensive private communications may persuade a relatively broadbased segment of the populace in the home country that liberalization is an appropriate policy. To allow for these possibilities, we have gathered data on business contacts (proxied here as direct bilateral trade links) and estimates of telephone traffic across pairs of countries. Once again, we weight the policy in the foreign country by the intensity of these communication channels.

We have also argued that information is gleaned from appropriate analogies and that policy changes in countries sharing common cultural traits have greater information content than do others. Good measures of cultural reference groups are difficult to pin down, but ideally we seek measures that tap perceived similarity of values and shared identity across countries. Common dominant language, common colonial heritage, and common dominant religion come close to capturing these shared orientations. Dominant language may also reflect communication channels, and common colonial heritage may pick up a number of structural similarities that on balance may be more historical than cultural. Dominant religion, on the other hand, should be a fairly good measure of the identity and values held by a society and a sense of cultural connectedness with other nations with similar spiritual commitments. ${ }^{17}$ For each language, colonial, or religious grouping we compute yearly means as described above. Note that these three variables, although quite similar, correlate only between -0.03 and 0.43 when combined with the dependent variable as described above (i.e., as $W y$ ).

\section{Control Variables}

Economic Shocks. It is certainly likely that policy transitions are influenced by conditions that have nothing to do with policy diffusion as we have defined it. The most likely alternative explanation is that governments, especially those in close regional proximity, face similar economic conditions and, therefore, find it independently rational to respond in similar ways.Currency crises, for example, may be a reason to restrict cap-

of PTA members) is not. Thus expressed, diffusion via communication among PTA members can be distinguished from the original decision to join the PTA in the first place.

17 On the link between cultural and, especially, religious values and economic liberalization, see, for example, Shalev 1997. ital outflows or an impetus for reform. Variation in world interest rates could cause regionwide capital outflows, capital and current account deterioration, and exchange rate pressure (Bartolini and Drazen 1976), with predictable pressures on policy. Similarly, robust growth rates or an improving balance of payments could increase policy makers' confidence in liberalization (Goodman and Pauly 1993; but see Haggard and Maxfield 1996).

In order to test these hypotheses, we enlist global and country-specific economic variables with a close association with liberalization. We include a lagged measure of currency crises/speculative attacks collected by David Leblang (2003) and based on Eichengreen, Rose, and Wyplosz (1995), which measures abnormally strong market pressures for currency depreciation. We control for world interest rates (using U.S. interest rates as a proxy), for each country's current account balance as a proportion of GDP (lagged two periods to minimize problems of endogeneity), and for GDP per capita (a rough indicator of developmental level [Johnston and Tamirisa 1998]). We control for the business cycle, using a measure of change in GDP growth. If policy liberalization and restriction are simply an uncoordinated response to financial or economic conditions, we should see strong effects for this battery of variables. To the extent that these conditions cluster in time and space, these controls should differentiate our diffusion mechanisms from explanations for clustering based on commonly experienced shocks.

External Political Pressure. A second sort of exogenous external shock for which we control is inspired by traditional theories of international relations. International politics often involve power relationships in which decisions made by weak or vulnerable states are the result of hegemonic pressure. One possibility is that the United States - the avatar of economic liberalism in the postwar period-has used its influence to prevail upon countries to announce policies that they would not have embraced otherwise. For example, the United States has reportedly pressed Chile and Singapore recently to liberalize further their capital accounts as a condition of free trade negotiations (Economist 2003:15). We therefore control for the proportion of each country's trade with the United States, as well as a partnership with the United States in a preferential trade arrangement or bilateral investment treaty. We even experiment with a dummy variable identifying years in which a Republican administration was in charge, on the theory that the United States' influence might differ depending on the partisan orientation of the president. As it is also possible that creditors with an interest in liberalization work through dominant international institutions, we control for the use of IMF credits, as well as an overall measure of overseas development assistance per capita (which includes actual multilateral and bilateral aid disbursed). As an alternative to the diffusion processes we have outlined here, governments might simply be responding to pressures by their creditors to liberalize their economies. 
This effect should be especially strong when members need to draw upon negotiated external resources.

Domestic Political Economy. Another possibility is that comparative political economy is sufficient to explain policy transitions. Domestic preferences, capacities, and institutions themselves may be correlated over time or spatially, producing a pattern that resembles policy diffusion. If the underlying political-economic conditions common to many states in a particular region "coevolve" over time, we could mistakenly be focused on policy diffusion when we should be looking at political, institutional, or developmental diffusion. Economic policy liberalization may simply be the result of independent decision making in similar domestic political/institutional contexts.

We therefore control for a set of measures that captures both the nature of "demands" the polity might make and the institutional landscape that translates those demands into policy. The extent to which the polity is likely to demand more open policies is approximated by the penetration of international trade, measured here in the traditional way (imports plus exports as a proportion of GDP). Garrett, Guisinger, and Sorens (2000) find that democracy is associated with a lower probability that a developing country will liberalize the capital account. This finding may well be due to the difficulty of reconciling democratic politics with popular demands in developing countries. We therefore include a measure of democracy (see Elkins 2000). La Porta et al. (1997) have argued that the nature of the legal system has a good deal to do with the protection of property rights. Common law systems, they claim, better protect investors and facilitate litigationbased rather than regulatory approaches to property rights. We hypothesize, therefore, that common law countries will be more likely to liberalize and less likely to restrict their financial markets in the ways examined here. Furthermore, certain institutional magnets for international capital might encourage the process of liberalization. Sylvia Maxfield (1997) has argued that an independent central bank-often credited with keeping inflation in check-is likely to attract external capital. Central bank independence may therefore underpin a government's confidence in liberalizing the flow of capital. We include data from McNamara and Castro (augmenting earlier work by Cukierman [1992]) that document major episodes of moves to make the central bank more independent. And by including a measure of the ruling party's level of nationalism, we consider the possibility that nationalist-leaning governments will be reluctant to initiate liberalization (see, however, Helleiner 2002).

Geography. Geography alone may continue to exercise an independent influence on economic policy diffusion through mechanisms that we have not explicitly considered. We experiment with two geographical variables-the logged distance between capitals and common borders. Our inclusion of spatial variables in a fully specified model allows us to isolate the effect that is due exclusively to changing material or reputational payoffs and informational influences that would otherwise be summarized in a geography term. This strategy helps to distinguish the diffusion mechanisms we are interested in from mere clustering.

It is important to keep in perspective just what we are trying to accomplish by the fullest possible specification of alternative hypotheses. The challenge is to parse out diffusion mechanisms from other plausible explanations for policy choice. The best way to demonstrate the likely causal impact of diffusion is to remove alternative explanations for the mere clustering of liberalization policies in time and space. If the weight of the evidence suggests that these controls outperform the channels of international diffusion theorized here, then we can be satisfied that traditional approaches to the political economy of liberalization are apt.

Table 1 summarizes the mechanisms, concepts, and measures in the model and presents their summary statistics.

\section{Sampling and Estimation}

Our sample includes as many as 182 IMF-member states with yearly observations from 1967 to $1996 .{ }^{18}$ We measure our dependent variables annually in binary form (see above). To model policy transitions, we employ a semi-Markov model, which is commonly used for estimating transitions among mutually exclusive states of being. This approach allows us to consider transitions in both directions as well as vacillations between policies (see Allison 1984). We run two hazard models for each dependent variable: one for transitions to liberal policies and one for transitions from liberal policies. We do not have especially strong distributional assumptions except that we expect that there will be some effect of time on the hazard rate. We use a Weibull survival model, but a Cox proportionate hazard model, on which Figures 3 and 4 are based, are substantively identical.

Incorporating spatial variables introduces a number of statistical complications. ${ }^{19}$ One is that spatial lags, as weighted averages of the dependent variable in the "neighborhood," often capture omitted variables that are highly correlated with membership in the group. ${ }^{20}$ Specifying the model as completely as possible is important. We are reasonably confident that we have identified some important predictors of liberalization, but no model is fully specified and caution is in order before inferring strong effects for diffusion. Multicollinearity is another potential concern with this type of analysis. As noted above, networks of influence tend to overlap. For example, countries that are geographically

\footnotetext{
${ }^{18}$ Our data are both left and right censored: Roughly 100 governments are under observation since the beginning of our analysis time (1967) and another 80 or so enter the analysis in the 1970s. Except in the case of state dissolution, all remain at risk after 1997.

${ }^{19}$ See Anselin 1988 for a discussion of these issues with respect to spatial terms and Blalock 1984 or Przeworski 1974 on contextual variables more generally.

${ }^{20}$ For this reason, many spatial models of this kind use 2SLS or even 3SLS estimators, an approach that comes with its own set of complications, especially in event history models.
} 
clustered are also likely to be important trade partners, competitors, or cultural peers. Indeed, this is the case, but not to an alarming degree. The correlations across the diffusion variables range from -0.03 to 0.43 .

\section{FINDINGS}

What conditions lead to policy transitions, whether toward liberalization or toward restrictions? Table 2 reports the Weibull hazard ratios for each of the six equations. ${ }^{21}$

\section{Conditions That Affect Material and Reputational Payoffs: Economic Competition and Global Norms}

The most pronounced effect on policy transition comes from economic competition, most notably competition for global capital. Governments clearly tend to liberalize when their competitors do. The influence of policy change for countries with the same risk ratings is correctly signed in all six models and is significant at least at the $90 \%$ confidence level in all cases (Table 2). ${ }^{22}$ Furthermore, when we substituted our index of comparable foreign direct investment venues (based on education of the work force and development of infrastructure), the results were correctly signed in all six models and statistically significant in the case of capital control liberalization ${ }^{23}$ - precisely where the theoretical case for competition is strongest.

Trade competition, on the other hand, is a less convincing causal mechanism, theoretically and empirically. Liberalization among countries that compete for the same export markets is quite likely to be important with respect to liberalization of the capital account, but the effects are ambiguous in the other cases. When we substituted the measure of sectoral competition, all results were statistically insignificant. If these policies are linked to economic competition, it seems likely that the desire to attract capital is a far more powerful motive than trade competition.

What are the sizes of these effects? The hazard ratios in Table 3 can be interpreted as the effect on the odds of transition associated with a one-unit move on the dependent variable. Remember that each of the diffusion

\footnotetext{
${ }^{21}$ Hazard ratios can be roughly understood as the change in the odds of transition associated with a one-unit change in the explanatory variable. Therefore, hazard ratios over one represent an increased probability of transition; of zero to one, a decreased probability of transition; and of one, zero effect. For the transitions to restrictive states, we reverse the scoring of the diffusion variables (originally scored as the weighted proportion of liberal policies) to be the weighted proportion of restrictive policies. Accordingly, the estimates of diffusion effects in Table 3 should be in the same direction for both transitions. Not so for the control variables.

22 This finding is robust (and nearly identical) to the use of an alternative dataset for unification of exchange rates based on Reinhart and Rogoff 2002. Using those data, we estimate the hazard ratio for the effect of other countries with a similar credit rating to be 1.756 $(p<0.05)$ for unification and $1.419(p<0.10)$ for transition to a multiple rate system.

${ }^{23}$ The desirability of venue index returned a hazard ratio of 1.414 $(p<0.10)$.
}

variables has been rescaled to range from 0 to 10 , so that each unit on these variables represents 10 percentage points. Thus, if we consider the policies of capital competitors, the model suggests that on average a shift of 10 percentage points in the percentage of one's competitors with a liberal policy will render a government anywhere from 1.8 (capital account) to 2.1 (exchange rates) times as likely to shift to a liberal policy. These are fairly strong effects, as one can illustrate by plotting survival curves for different conditions of competition. (In event history analysis, survival curves depict the probability of "survival," that is, the probability of not having shifted to a new state or policy, at each time point in the analysis.) Figure 3 plots survival curves based on estimates of the effect of capital competition on the probability of shifting to a liberal capital account policy (that is, the first model in Table 3). The curves represent two conditions-one in which none of a governments competitors has a liberal policy and another in which one half of competitors have liberal policies. All other variables in the model are held at their means. The effects appear to be quite significant. Almost $30 \%$ of those with liberalized competitors would have shifted to liberal policies by the mid 1980 s, while less than $5 \%$ of those without liberalized competitors would have shifted by that time. This effect appears especially large if we contrast it with that of a currency crisis (Figure 4).

While the effect of competition appears significant, global norms - operationalized as the share of countries globally assuming a particular policy stance-had few discernible effects, and the one statistically significant result was in the unexpected direction. This outcome suggests that it is far more likely that policy diffusion takes place via specific conduits carved out by economic competition, and not as a result of diffuse signals sent by the world at large.

\section{Diffusion Due to New Information: Conspicuous Success, Communication Channels, and Cultural Reference Groups}

The hypothesis that success attracts adherents is well supported by these results. Table 2 establishes a fairly clear pattern: Governments tend to implement the policies chosen by other "successful" countries (with the exception of capital account liberalization). In four cases, there is evidence of a strong tendency to follow the policies taken by the highest growth countries, measured here as the fastest-growing decile. ${ }^{24}$ This is highly suggestive evidence that economic policy making of the most "successful" becomes data for updating policy beliefs - and, ultimately, actions - of governments elsewhere. If the proportion of countries in the top decile in growth with a liberal exchange rate policy changes from $25 \%$ to $75 \%$, the probability of a transition among other countries increases by 36 percentage points.

Communication networks add little to the unchanneled Bayesian updating model. Individual measures of private communication via telephone generally

\footnotetext{
${ }^{24}$ This finding applies to the highest-growth countries. When the cutoff was made at the median, these effects were not significant.
} 


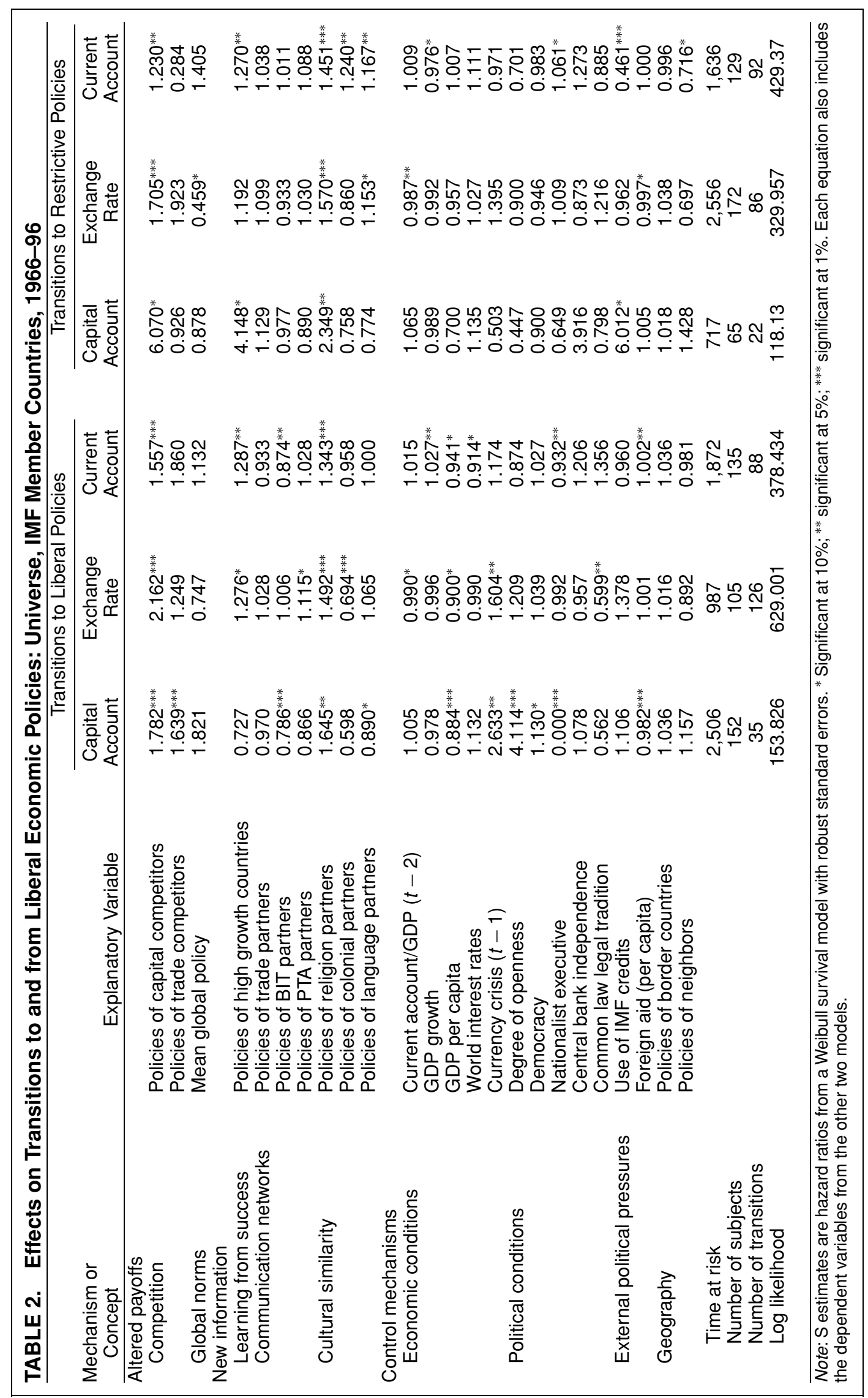




\begin{tabular}{|c|c|c|c|c|c|c|}
\hline & \multicolumn{3}{|c|}{ Transitions to Liberal Policies } & \multicolumn{3}{|c|}{ Transitions to Restrictive Policies } \\
\hline & $\begin{array}{l}\text { Capital } \\
\text { Account }\end{array}$ & $\begin{array}{l}\text { Exchange } \\
\text { Rate }\end{array}$ & $\begin{array}{l}\text { Current } \\
\text { Account }\end{array}$ & $\begin{array}{l}\text { Capital } \\
\text { Account }\end{array}$ & $\begin{array}{l}\text { Exchange } \\
\text { Rate }\end{array}$ & $\begin{array}{l}\text { Current } \\
\text { Account }\end{array}$ \\
\hline $\begin{array}{l}\text { Log likelihood of full model } \\
\text { Constrained models }\end{array}$ & 153.988 & 628.616 & 379.005 & 116.229 & 329.877 & 426.308 \\
\hline \multicolumn{7}{|l|}{$\begin{array}{l}\text { Constrained models } \\
\text { Altered Payoffs }\end{array}$} \\
\hline Competition $=0$ & $\begin{array}{c}26.87(2) \\
p=0.00\end{array}$ & $\begin{array}{c}25.62(2) \\
p=0.00\end{array}$ & $\begin{array}{c}64.43(2) \\
p=0.00\end{array}$ & $\begin{array}{l}1.44(2) \\
p=0.48\end{array}$ & $\begin{array}{c}33.21(2) \\
p=0.00\end{array}$ & $\begin{array}{l}6.24(2) \\
p=0.04\end{array}$ \\
\hline \multicolumn{7}{|l|}{ New information } \\
\hline Learning from success $=0$ & $\begin{array}{l}0.96(1) \\
p=0.32\end{array}$ & $\begin{array}{l}2.82(1) \\
p=0.09\end{array}$ & $\begin{array}{l}6.51(1) \\
p=0.01\end{array}$ & $\begin{array}{l}3.00(1) \\
p=0.08\end{array}$ & $\begin{array}{l}0.75(1) \\
p=0.39\end{array}$ & $\begin{array}{l}3.52(1) \\
p=0.06\end{array}$ \\
\hline Official communication $=0$ & $\begin{array}{c}12.58(2) \\
p=0.01\end{array}$ & $\begin{array}{l}3.50(2) \\
p=0.17\end{array}$ & $\begin{array}{l}6.03(2) \\
p=0.49\end{array}$ & $\begin{array}{l}0.15(2) \\
p=0.92\end{array}$ & $\begin{array}{l}0.68(2) \\
p=0.71\end{array}$ & $\begin{array}{l}1.23(2) \\
p=0.54\end{array}$ \\
\hline Cultural similarity $=0$ & $\begin{array}{c}11.44(3) \\
p=0.01\end{array}$ & $\begin{array}{c}10.16(3) \\
p=0.01\end{array}$ & $\begin{array}{l}18.07(3) \\
p=0.00\end{array}$ & $\begin{array}{l}5.22(3) \\
p=0.15\end{array}$ & $\begin{array}{l}19.08(3) \\
p=0.00\end{array}$ & $\begin{array}{l}46.8(3) \\
p=0.00\end{array}$ \\
\hline \multicolumn{7}{|l|}{ Control mechanisms } \\
\hline Economic determinants $=0$ & $\begin{array}{c}13.68(3) \\
p=0.18\end{array}$ & $\begin{array}{c}14.29(3) \\
p=0.02\end{array}$ & $\begin{array}{c}14.85(3) \\
p=0.01\end{array}$ & $\begin{array}{l}4.45(3) \\
p=0.48\end{array}$ & $\begin{array}{c}10.05(3) \\
p=0.07\end{array}$ & $\begin{array}{l}4.82(3) \\
p=0.43\end{array}$ \\
\hline External political pressures $=0$ & $\begin{array}{l}9.70(2) \\
p=0.01\end{array}$ & $\begin{array}{l}0.10(2) \\
p=0.74\end{array}$ & $\begin{array}{l}4.53(2) \\
p=0.03\end{array}$ & $\begin{array}{l}2.95(2) \\
p=0.22\end{array}$ & $\begin{array}{l}2.87(2) \\
p=0.23\end{array}$ & $\begin{array}{l}0.01(2) \\
p=0.90\end{array}$ \\
\hline Political determinants $=0$ & $\begin{array}{c}157.64(4) \\
p=0.00\end{array}$ & $\begin{array}{l}9.93(4) \\
p=0.07\end{array}$ & $\begin{array}{l}8.75(4) \\
p=0.11\end{array}$ & $\begin{array}{l}2.63(4) \\
p=0.75\end{array}$ & $\begin{array}{l}2.89(4) \\
p=0.72\end{array}$ & $\begin{array}{l}6.22(4) \\
p=0.28\end{array}$ \\
\hline Geography $=0$ & $\begin{array}{l}0.31(2) \\
p=0.85\end{array}$ & $\begin{array}{l}0.38(2) \\
p=0.82\end{array}$ & $\begin{array}{l}0.31(2) \\
p=0.85\end{array}$ & $\begin{array}{l}0.50(2) \\
p=0.78\end{array}$ & $\begin{array}{l}2.63(2) \\
p=0.62\end{array}$ & $\begin{array}{l}3.62(2) \\
p=0.16\end{array}$ \\
\hline
\end{tabular}

FIGURE 3. The Probability of Maintaining a Restrictive Capital Account: The Effect of Policies of Capital Competitors

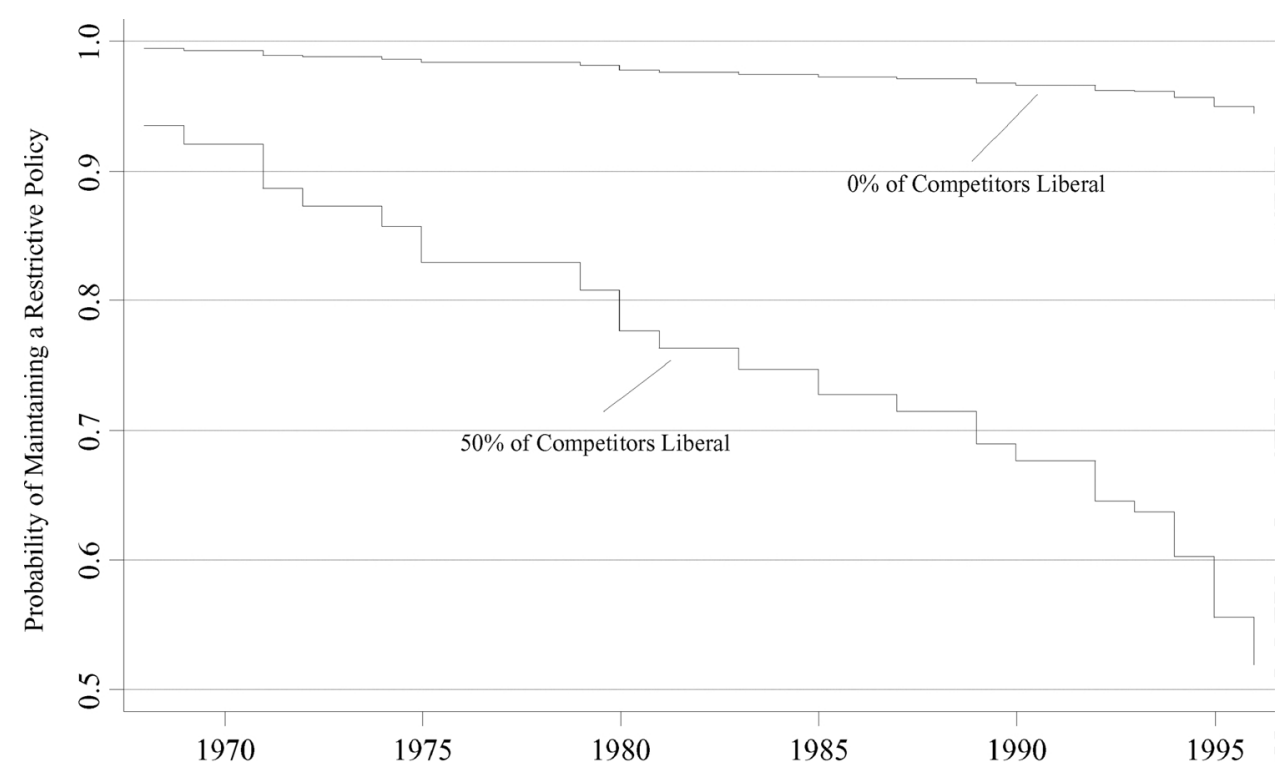

Note: Survival curve calculated from Cox proportional hazard estimates. All variables except Policies of capital competitiors held at their means. 


\section{FIGURE 4. The Probability of Maintaining a Restrictive Capital Account: The Effect of a Currency Crisis in the Preceding Year}

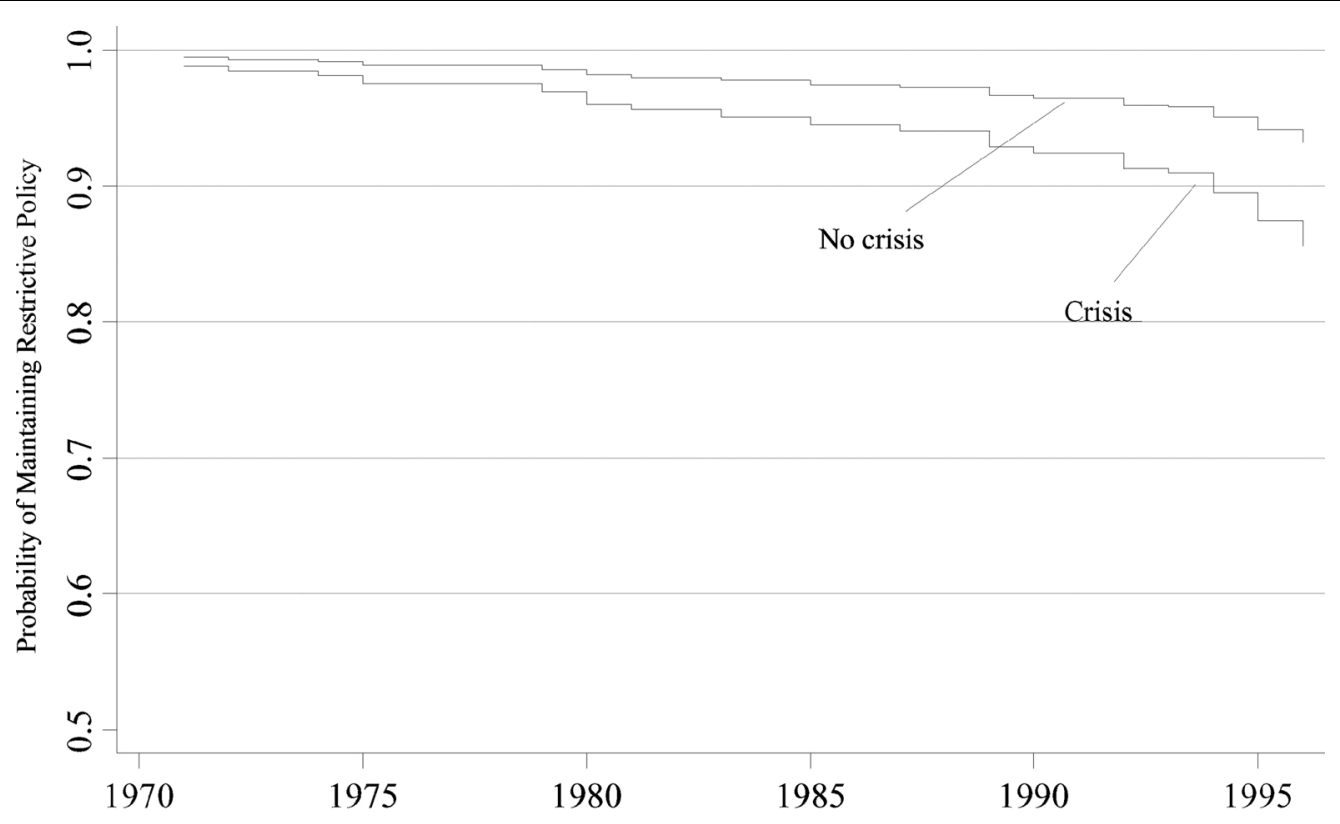

Note: Survival curve calculated from Cox proportional hazard estimates. All variables except currency crisis held at their means.

had no effects and were dropped from the models. Private business contacts (proxied here as major import and export partners) produce results that are inconsistently signed and yield no clear insights. Official contacts fared little better. Common membership in a PTA may predict transitions to unified exchange rate systems but otherwise have no discernible effects. The policies of countries with which a country has signed a bilateral investment treaty appear, if anything, to have a negative effect on policy (statistically significant in the cases of capital account liberalization and exchange rate unification). We believe that this result probably has to do with adverse selection effects for signing a BIT in the first place (Elkins, Guzman, and Simmons 2003). Overall, we find no compelling evidence that communication ties alone affect the decision to liberalize or to restrict external monetary and financial policies.

Consider next the effects of cultural reference groups. We have argued that governments may reasonably search out new information from cases perceived to have cultural relevance to their own situation. The most conspicuous finding here is that the policies of countries with similar dominant religion are remarkably influential. The effects of the other two measures-common language and common colonial heritage-wash out in all but a few cases (note that policies among similar language and religious groupings are positively but mildly correlated at 0.29 ). The effects of the policies of countries with shared religious values are significantly positive for each of the six policy transitions. ${ }^{25}$ Moreover, the size of this effect is impor-

\footnotetext{
${ }^{25}$ This finding is robust (and nearly identical) to the use of an alter-
} native dataset for unification of exchange rates based on Reinhart tant. In fact, a move of one standard deviation one way or another on the mean policy of countries with similar dominant religions is associated with a change of roughly 15 points in the probability of a country's policy transition. Cultural lenses that influence acceptance of a particular economic policy model may provide far more purchase on actual policy choices than the recent political economy literature has allowed.

\section{Control Variables}

Finally, we consider the effects of the control variables. The hypothesis that governments are responding to various economic shocks is not especially well supported. The directions of effects are generally as one would expect, however. High world interest rates may tend to decrease the probability of liberalization of the current account. GDP growth may encourage and help maintain current account liberalization-its only statistically significant effect. Current account surpluses tend to be associated with policy inertia with respect to the unification of the exchange rate regime (there is a significant reduction in the hazard rate for both liberalization and restriction), whereas deficits tend to stimulate policy change in both directions. Currency crises seem to be associated with liberalization in the following period, a result that was statistically significant for both the capital account and exchange rate unification.

and Rogoff 2002. Using those data, we estimate the hazard ratio for the effect of other countries of the same dominant religion to be $1.91(p<0.10)$ for unification and $1.184(p<0.05)$ for transition to a multiple rate system. 
Developing countries as measured by per capita GDP almost certainly find it more difficult to make liberal transitions (statistically significant in every case), but the hazard ratios for implementing restrictions, although not statistically significant, indicate by their consistency that developing countries may find it harder to implement policy transitions at all.

The results from the hegemonic variables are mixed. In none of the models did borrowing from the IMF increase the likelihood of a liberal policy shift. On the other hand, as one might expect, a contract with the IMF appears to be associated with a reluctance to restrict the current account. The use of IMF credits is associated with restrictions on the capital account, which is probably indicative of capital flight problems that precipitated extramarket borrowing in the first place. There is also some evidence that overseas development assistance is in some way related to policy shifts in these three areas. Dependence on such aid (which includes both multilateral and bilateral sources) is associated with liberalization of the current account and eschewing of multiple exchange rate regimes, but it is also associated with a reduction in the probability of liberalizing capital markets. In order to test hegemonic arguments further, we experimented with models that controlled for share of exports to the United States, share of imports from the United States, and joint membership with the United States in a preferential trade arrangement or in a bilateral investment treaty. We also entered all of these variables for relations with the $\mathrm{Eu}$ ropean Union. We then controlled for the party affiliation of the U.S. president. None of these specifications returned statistically significant results, and they were dropped from the model. Overall, it is difficult to sustain the argument that the waves of liberalization and restriction in these policy areas have been systematically influenced by direct or organizationally mediated hegemonic pressure.

The domestic political variables also behave unexpectedly weakly. As the political economy literature has long held, there is evidence that people residing in open economies demand and probably get greater policy liberalization, at least in the case of the capital account, and revert to restrictions with less frequency. Nationalist governments are much less likely to liberalize (especially on the capital account). Democracies tend to favor liberal transitions, although these results are statistically significant only for the capital account. The effects of legal heritage-hypothesized to reflect attitudes toward regulation and property rights-were inconsistent and, with one exception in the wrong direction, insignificant. Improvements in central bank independence were similarly not associated with particular policy demarches.

Once we control for other factors, it appears that geography per se is not a convincing explanation of policy diffusion. The apparently strong geographical effects in Figure 1 are obliterated by the functional and cultural relationships described above. With one minor exception in the wrong direction, neither geographical distance nor status as a bordering country had any independent effect on policy stance.
Another way to look at the plausibility of the diffusion mechanisms we have proposed is to examine their effects as a block. This is useful because we want to make claims about broad mechanisms for which we employ related, but disaggregated measures. In Table 3, we summarize the strength of these blocks by comparing the full model with nested models in which the blocks of diffusion effects are constrained to zero. The likelihood-ratio test of such comparisons indicates the improvement in fit associated with the addition of each block of variables. ${ }^{26}$

Viewed in this way, the aggregate effects of clusters of measures are quite robust. Economic competition is an especially important and consistent part of the explanation for change in both directions for each of the three policy areas: In five of the six transition models, the block of measures of competition is almost certainly significant, with the only exception being transitions to restrictive policies in the current account. The variables that represent cultural similarity taken as a block are consistently important in explaining policy choice, with the possible exception of capital account liberalization. On the other hand, communication networks do not clearly add much explanatory power to policy choice. As we had only one indicator of learning from success, the results in Table 3 reflect the findings reported in Table 2.

The blocks of control variables are much less convincingly associated with policy choice in these areas. The economic variables jointly contribute to an improvement in model fit in only half of the cases. The domestic political and institutional variables do a relatively good job at improving the fit for liberal transitions but fail to add anything to our understanding of policy restrictions. Hegemonic pressure seems to help explain capital and current account liberalization, but our earlier models uncovered a counterintuitive direction to these influences in the former case. Geography alone never stands up to scrutiny.

\section{CONCLUSIONS}

There are good reasons to believe that governments are sensitive to external signals to liberalize and to restrict their monetary and financial policies. Temporal and spatial clustering support the proposition that something systematic must be driving states' policies in this way. Indeed, this characterization is easy to accept intuitively. Scholars and laypersons alike find it easy to grasp the competitive implications for Mexico of free trade between the United States and Canada (Gruber 2000), as well as the socially emulative impulses of developing countries (Finnemore 1996). Much is at stake, theoretically and practically, in recognizing the importance of policy diffusion to the current state of globalization. The recent political economy literature has concentrated primarily on the domestic sources of foreign economic policy or, at most, economic policy

\footnotetext{
26 The null hypothesis of these tests is that the joint effect of the block of variables is zero. A rejection, therefore, suggests that the variables improve the fit of the model.
} 
choice in response to price signals from the unmediated international economy. Purely economic explanations of policy coordination-theories of optimal currency areas, for example-have consistently failed to capture government choices on the ground. ${ }^{27}$ Meanwhile, international financial markets have been extolled or vilified by heavily ideological accounts that tend to hinder rather than assist in creative analysis. Furthermore, some scholars and observers have attributed policy liberalization to exogenous pressures from the IMF as the organizational embodiment of the "Washington Consensus." The analysis in this paper suggests that these approaches do not sufficiently explain why governments decide to open or restrict their economies.

We have explored two broad sets of mechanisms that might explain patterns that appear to involve policy diffusion among countries: altered payoffs and new information. As an example of changing payoffs, competition for international capital seems to be an especially compelling explanation for the international diffusion of liberal economic policy. Across all policy areas, policy liberalization is highly correlated with the orientation of other governments that compete for the same slice of global capital. Could this simply be due to the fact that similarly rated countries are economically similar in a number of ways, and so have independently similar incentives to open and restrict their capital and current accounts? This is possible, though it is rendered much less likely by the inclusion of a battery of economic controls (growth, balance of payments, world interest rates, currency crises, developmental level) that should to some extent control for this problem. We also found that a completely different specification of capital competitors, aimed more directly at competition for foreign direct investment and based on similar levels of education and infrastructure, yielded results in the correct direction, which were highly significant for liberalization of the capital account. The relationship between competition for capital and policy diffusion is so empirically strong and theoretically plausible in these tests that it should be a high priority for future research.

Next we tested arguments that new information and learning contribute to economic policy diffusion. Empirical work on learning must be grounded in plausible, observable proxies for this essentially psychological process. Our strategy has been to look for the observable implications of learning, which we believe in the first instance are influenced by examples of conspicuous economic success. Indeed, policies of the highest growth countries did have a significant impact on four of the policy choices examined here. Interestingly, this finding did not hold for capital account liberalization. Given the recent acknowledgment of such proliberalization institutions as the IMF and the Economist newspaper that capital account liberalization makes

\footnotetext{
27 Of the many studies that fail to explain extant currency patterns based on OCA theory, see Ghosh and Wolf (1994), who find that neither Europe nor the United States forms an optimum currency area; for both regions the costs of adopting a single currency exceeds estimates of the transaction cost savings.
}

sense only in specific macroeconomic and regulatory contexts, this finding is actually quite encouraging.

Few political economists, (though of course many more sociologists) would have nominated broad cultural orientation as a central explanation for policy diffusion. The results here, however, are difficult to ignore. Our results show that governments tend to liberalize and to restrict the capital account, current account, and exchange rate regime along the lines of countries with which they share a religious identity, when we control for a wide range of other factors. A striking finding is that this relationship holds in all three policy areas, and symmetrically for both liberalization and restriction. The evidence supports neither the "world culture" sociologists, who emphasize the irrationality of absorbing global culture willy-nilly, nor the political economists, who remove culture from the calculus of policy choice altogether. We suggest that governments systematically consider the lessons their cultural peers have to offer when fashioning their own economic policy choices. Of course, religion should be thought of as just one indicator that taps the broader value orientation or cultural identity of a society. Note also that we are not arguing that religion speaks directly to the question of capital controls or exchange rate arrangements. These results do suggest, though, that values common to a particular religious tradition may shape attitudes toward risk, individualism, equality, and materialism generally. Governments tend to take these shared attitudes into account when searching for appropriate models in the absence of perfect (or perfectly understood) information. Cultural values may be a fundamental source of identity for governments as much as for individuals, with consequences for highly material arenas of policy choice.

One thing is clear: Economics and comparative political economy can take us only so far in understanding the ebb and flow of foreign economic policy liberalization over the past three decades. The apparent diffusion of policy choice over this time demands explicitly international or indeed transnational theory and testing. As we think in these directions, we may uncover underemphasized sources of authority that structure competition and channel the search for appropriate models of foreign economic policy. Research into the dynamics of globalization and its underlying governance structures should push us to understand how and why this takes place.

\section{REFERENCES}

Alesina, Alberto F., Vittorio Grilli, and Gian Maria Milesi-Ferretti. 1994. "The Political Economy of Capital Controls." In Capital Mobility: The Impact on Consumption, Investment, and Growth, ed. Leonardo Leiderman and Assaf Razin. Cambridge: Cambridge University Press.

Allison, Paul D. 1984. Event History Analysis and Regression for Longitudinal Event Data. Beverly Hills, CA: Sage.

Amin, Galal A. 1981. "Some Economic and Cultural Aspects of Economic Liberalization in Egypt." Social Problems 30 (2): 43041.

Anselin, Luc. 1988. Spatial Econometrics: Methods and Models. Dordrecht, The Netherlands: Kluwer Academic. 
Axelrod, Robert. 1997. "The Dissemination of Culture-A Model with Local Convergence and Global Polarization." Journal of Conflict Resolution 41 (2): 203-26.

Bartolini, Leonardo, and Allan Drazen. 1997a. "Capital-Account Liberalization as a Signal." American Economic Review 87 (1): 138-54.

Bartolini, Leonardo, and Allan Drazen. 1997b. "When Liberal Policies Reflect External Shocks, What Do We Learn?" Journal of International Economics 42 (3-4): 249-73.

Beng-Huat, Chua. 1999. "Asian-Values. Discourse and the Resurrection of the Social." Positions 48 (4): 573-92.

Bennett, Colin. 1991. "How States Utilize Foreign Evidence." Journal of Public Policy 11 (1): 31-54.

Blalock, Hubert M. 1984. "Contextual Effects Models: Theoretical and Methodological Issues." Annual Review of Sociology 10: 353-72.

Brady, Henry E., and Paul M. Sniderman. 1985. "Attitude Attribution: A Group Basis for Political Reasoning." American Political Science Review 79: 1061-78.

Cantor, Richard, and Frank Packer. 1996. "Determinants and Impact of Sovereign Credit Ratings." Economic Policy Review 2 (2): $37-53$.

Cargill, Thomas F., and Elliott Parker. 2001. "Financial Liberalization in China: Limitations and Lessons of the Japanese Regime." Journal of the Asia Pacific Economy 6 (1): 1-21.

Central Intelligence Agency. 1999. World Factbook. http://www.odci. gov/cia/publications/factbook/.

Checkel, Jeff. 1993. "Ideas, Institutions, and the Gorbachev Foreign Policy Revolution." World Politics 45: 271-300.

Chun, Allen. 2000. "Democracy as Hegemony, Globalization as Indigenization, or the 'Culture' in Taiwanese National Politics." Journal of Asian and African Studies 35 (1): 7-27.

Crook, Clive. 2003. "A Cruel Sea of Capital." Economist, 1 May.

Coleman, James S. 1960. "The Adolescent Subculture and Academic Achievement." American Journal of Sociology 65 (4): 337-47.

Collier, David, and R. E. Messick. 1975. "Functional Requisites versus Diffusion: Testing Alternative Explanations of Social Security Adoption." American Political Science Review 69: 12991315.

Cooper, Richard N. 1968. The Economics of Interdependence: Economic Policy in the Atlantic Community. New York: McGraw-Hill for the Council on Foreign Relations.

Cukierman, Alex. 1992. Central Bank Strategy, Credibility, and Independence: Theory and Evidence. Cambridge, MA: MIT Press.

Davis, Gerald F., and Henrich R. Greve. 1997. "Corporate Elite Networks and Governance Changes in the 1980s." American Journal of Sociology 103: 1-37.

Deutsch, Karl W. 1953. Nationalism and Social Communication: An Inquiry into the Foundations of Nationality. New York: Wiley.

Dobson, Wendy, and Gary Clyde Hufbauer. 2001. World Capital Markets: Challenge to the $G-10$. Washington, DC: Institute for International Economics.

Edwards, A. C., and Sebastian Edwards. 1992. "Markets and Democracy-Lessons from Chile." World Economy 15 (2): 20319.

Eichengreen, Barry, Andrew Rose, and Charles Wyplosz. 1995. "Exchange Market Mayhem: The Antecedents and Aftermath of Speculative Attacks." Economic Policy 21: 45-61.

Elkins, Zachary. 2000. "Gradations of Democracy? Empirical Tests of Alternative Conceptualizations." American Journal of Political Science 44 (2): 293-300.

Elkins, Zachary, Andrew Guzman, and Beth A. Simmons. 2003. "The Diffusion of Bilateral Investment Treaties: An Empirical Analysis." Presented at the Conference on International Diffusion of Political and Economic Liberalization, Weatherhead Center for International Affairs, Harvard University, October 3-4, 2003. Available at http://www.wcfia.harvard.edu/conferences/

Encarnation, Dennis J., and Mark Mason. 1990. "Neither MITI nor America: The Political Economy of Capital Liberalization in Japan." International Organization 44: 25-54.

Epstein, Gerald A., and Juliet Schor. 1992. "Structural Determinants and Economic Effects of Capital Controls in OECD Countries." In Financial Openness and National Autonomy: Opportunities and Constraints, ed. Tariq Banuri and Juliet Schor. Oxford: Clarendon Press.
Europa. 1999. Europa World Year Book 1999. London: Europa.

Finger, J. M., and M. E. Kreinin. 1979. "A Measure of 'Export Similarity' and Its Possible Uses." Economic Journal 89: 90512.

Finnemore, Martha. 1996. National Interests in International Society. Ithaca, NY: Cornell University Press.

Frieden, Jeffrey A. 1991. "Invested Interests: The Politics of National Economic Policies in a World of Global Finance." International Organization 45 (4): 425-51.

Garrett, Geoffrey, Alexandra Guisinger, and Jason P. Sorens. 2000 "The Political Economy of Capital Account Liberalization." Unpublished manuscript.

Ghosh, A. R., and H. C. Wolf. 1996. "On the Mark(s): Optimum Currency Areas in Germany.” Economic Modelling 13 (4): 56173.

Gleditsch, Kristian S., and Michael D. Ward. 2000. "War and Peace in Space and Time: The Role of Democratization." International Studies Quarterly 44 (1): 1-29.

Goff, Patricia M. 2000. "Invisible Borders: Economic Liberalization and National Identity." International Studies Quarterly 44 (4): 533 62.

Goodman, John, and Louis Pauly. 1993. "The Obsolescence of Capital Controls? Economic Management in an Age of Global Markets." World Politics 46: 50-82.

Gore, Charles. 2000. "The Rise and Fall of the Washington Consensus as a Paradigm for Developing Countries." World Development 28 (5): 789-804.

Granato, Jim, Ronald Inglehart, and David Leblang. 1996. "The Effect of Cultural Values on Economic Development: Theory, Hypotheses, and Some Empirical Tests." American Journal of Political Science 40 (3): 607-31.

Granovetter, Mark. 1978. "Threshold Models of Collective Behavior." American Journal of Sociology 83 (6): 1420-43.

Gray, Virginia. 1973. "Innovation in the States: A Diffusion Study." American Political Science Review 67: 1174-85.

Gruber, Lloyd. 2000. Ruling the World: Power Politics and the Rise of Supranational Institutions. Princeton, NJ: Princeton University Press.

Haas, Ernst B. 1959. The Future of West European Political and Economic Unity. Santa Barbara, CA: Technical Military Planning Operation, General Electric Company.

Haggard, Stephan, and Sylvia Maxfield. 1996. "The Political Economy of Financial Internationalization in the Developing World." International Organization 50 (1): 35-68.

Hague, Nadeem, Donald Mathieson, and Mark Nelson. 1997. "Rating the Raters of Country Creditworthiness." Journal of Finance and Development 10.

Hamada, Koichi. 1985. The Political Economy of International Monetary Interdependence. Cambridge, MA: MIT Press.

Helleiner, Eric. 2002. "Economic Nationalism as a Challenge to Economic Liberalism? Lessons from the 19th Century." International Studies Quarterly 46 (3): 307-29.

Huntington, Samuel P. 1991. The Third Wave: Democratization in the Late Twentieth Century. Norman: University of Oklahoma Press.

Iida, Keisuke. 1999. International Monetary Cooperation among the United States, Japan, and Germany. Boston: Kluwer Academic.

Jacoby, Wade. 2000. Imitation and Politics: Redesigning Modern Germany. Ithaca, NY: Cornell University Press.

Johnston, R. Barry, and Natalia T. Tamirisa. 1998. "Why Do Countries Use Capital Controls?” IMF Working Papers WP/98/181. Washington, DC: International Monetary Fund.

Kahneman, Daniel, Paul Slovic, and Amos Tversky. 1982. Judgment Under Uncertainty: Heuristics and Biases. Cambridge: Cambridge University Press.

Kaplinsky, Raphael. 2001. "Globalisation and Economic Security." IDS Bulletin 49 (6): 13-24.

King, Gary. 1989. "Event Count Models for International Relations: Generalizations and Applications." International Studies Quarterly 33: $123-47$.

Krasner, Stephen D. 1985. Structural Conflict: The Third World Against Global Liberalism. Berkeley: University of California Press.

La Porta, Rafael, Florencio Lopez-De-Silanes, Andrei Shleifer, and Robert W. Vishny. 1997. Legal determinants of external finance. Journal of Finance 52 (3): 1131-50. 
Leblang, David A. 1997. "Domestic and Systemic Determinants of Capital Controls." International Studies Quarterly 41 435-54.

Leblang, David A. 2003. "Is Democracy Incompatiable with International Economic Stability?” Manuscript. Department of Political Science, University of Colorado, Boulder.

Lupia, Arthur, and Mathew McCubbins. 1998. The Democratic Dilemma: Can Citizens Learn What They Need to Know? Cambridge: Cambridge University Press.

Majone, Giandomenico. 1989. Evidence, Argument, and Persuasion in the Policy Process. New Haven, CT: Yale University Press.

Marsden, Peter, and Noah Friedkin. 1993. "Network Studies of Social Influence." Sociological Methods and Research 22: $127-$ 51.

Maxfield, Sylvia. 1997. Gatekeepers of Growth: The International Political Economy of Central Banking in Developing Countries. Princeton, NJ: Princeton University Press.

McNamara, Kathleen R. 1998. The Currency of Ideas: Monetary Politics in the European Union. Ithaca, NY: Cornell University Press.

Meyer, John W., and Brian Rowan. 1977. "Institutionalized Organizations: Formal Structure as Myth and Ceremony." American Journal of Sociology 83: 340-63.

Mizruchi, Mark S. 1989. "Similarity of Political Behavior among Large American Corporations." American Journal of Sociology 95: 401-25.

O'Laughlin, John et al. 1998. "The Diffusion of Democracy, 19461994." Annals of the Association of American Geographers 88 (1): 545-74.

Powell, Walter W., and Paul DiMaggio. 1991. The New Institutionalism in Organizational Analysis. Chicago: University of Chicago Press.

Prasad, Eswar, Kenneth Rogoff, Shang-jin Wei, and M. Ayhan Kose. 2002. "Effects of Financial Globalization on Developing Countries: Some Empirical Evidence." International Monetary Fund (March 17, 2003). http:// www.imf.org/external/np/res/docs/ 2003/031703.pdf.

Przeworski, Adam. 1974. "Contextual Models of Political Behavior.' Political Methodology 1: 27-61.

Quinn, Dennis P. 1997. "The Correlates of Change in International Financial Regulation.” American Political Science Review 91: 53151.

Quinn, Dennis P., and Carla Inclan. 1997. "The Origins of Financial Openness: A Study of Current and Capital Account Liberalization." American Journal of Political Science 41: 771-813.

Reinhart, Carmen M., and Kenneth S. Rogoff. 2002. "The Modern History of Exchange Rate Arrangements: A Reinterpretation." NBER Working Paper No. 8963. http://papers.nber. org/papers/w8963.pdf.

Risse-Kappen, Thomas. 1994. "Ideas Do Not Float Freely: Transnational Coalitions, Domestic Structures, and the End of the Cold War." International Organization 48: 185-214.

Rogers, Everett M. 1995. The Diffusion of Innovations. 3rd ed. New York: Free Press.
Rogowski, Ronald. 1989. Commerce and Coalitions: How Trade Affects Domestic Political Alignments. Princeton, NJ: Princeton University Press.

Rose, Richard. 1993. Lesson Drawing in Public Policy. Chatham, NJ: Chatham House.

Rosenau, James N. 1990. Turbulence in World Politics, a Theory of Change and Continuity. Princeton, NJ: Princeton University Press.

Ruggie, John Gerhard. 1975. "International Responses to Technology: Concepts and Trends." International Organization 29 (3): 557 83 .

Schelling, Thomas C. 1978. Micromotives and Macrobehavior. New York: W. W. Norton.

Scott, W. Richard, John W. Meyer, et al., eds. 1994. Institutional Environment and Organizations: Structural Complexity and Individualism. Thousand Oaks CA: Sage.

Shalev, Michael. 1997. "Zionism and Liberalization: Change and Continuity in Israel's Political Economy." Humboldt Journal of Social Relations 47 (6): 219-59.

Simmons, Beth A. 1994. Who Adjusts? Domestic Sources of Foreign Economic Policy during the Interwar Years 1923-1939. Princeton, NJ: Princeton University Press.

Simmons, Beth A. 2000. "International Law and State Behavior: Commitment and Compliance in International Monetary Affairs." American Political Science Review 94: 819-35.

Soto, Marcelo. 2000. "Capital Flows and Growth in Developing Countries: Recent Empirical Evidence." OECD Development Center, Technical Paper No. 160. http://www.oecd.org/pdf/ M00006000/M00006207.pdf.

Starr, Harvey. 1991. "Democratic Dominoes: Diffusion Approaches to the Spread of Democracy in the International System." Journal of Conflict Resolution 35 (2): 356-81.

Stockman, Alan C., and Alejandro Hernandez. 1988. "Exchange Controls, Capital Controls, and International Financial Markets." American Economic Review 78 (3): 362-74.

Strang, D. 1991. "Adding Social Structure to Diffusion Models-An Event History Framework." Sociological Methods and Research 19: 324-53.

Tolbert, Pamela, and Lynne Zucker. 1983. "Institutional Sources of Change in the Formal Structure of Organizations: The Diffusion of Civil Service Reform, 1880-1935." Administrative Science Quarterly 28 (1): 22-39.

Wahba, Jackline, and Mahmoud Mohieldin. 1998. "Liberalizing Trade in Financial Services: The Uruguay Round and the Arab Countries." World Development 26 (7): 1331-48.

Walker, Jack L. 1969. "The Diffusion of Innovation among American States." American Political Science Review 63: 880-99.

Wasserman, Stanley, and Katherine Faust. 1994. Social Network Analysis: Methods and Applications. Cambridge: Cambridge University Press.

Westney, D. Eleanor. 1987. Imitation and Innovation: The Transfer of Western Organizational Patterns to Meiji Japan. Cambridge, MA: Harvard University Press.

Williamson, John. 1993. "Democracy and the Washington Consensus." World Development 21 (8): 1329-36. 